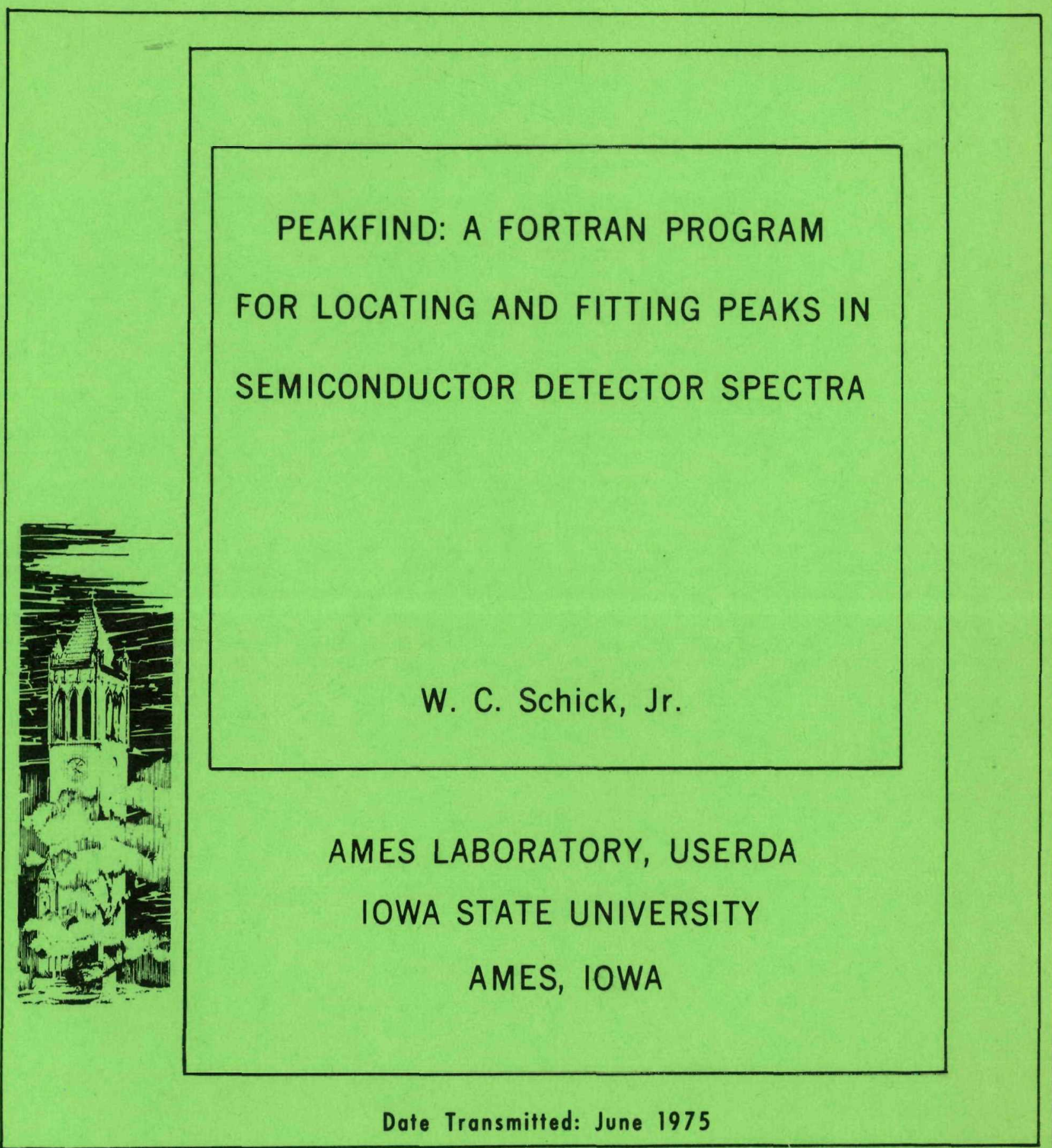

PREPARED FOR THE U. S. ENERGY RESEARCH AND DEVELOPMENT ADMINISTRATION UNDER CONTRACT W-7405-eng-82 


\section{DISCLAIMER}

This report was prepared as an account of work sponsored by an agency of the United States Government. Neither the United States Government nor any agency Thereof, nor any of their employees, makes any warranty, express or implied, or assumes any legal liability or responsibility for the accuracy, completeness, or usefulness of any information, apparatus, product, or process disclosed, or represents that its use would not infringe privately owned rights. Reference herein to any specific commercial product, process, or service by trade name, trademark, manufacturer, or otherwise does not necessarily constitute or imply its endorsement, recommendation, or favoring by the United States Government or any agency thereof. The views and opinions of authors expressed herein do not necessarily state or reflect those of the United States Government or any agency thereof. 


\section{DISCLAIMER}

Portions of this document may be illegible in electronic image products. Images are produced from the best available original document. 


\title{
PEAKFIND: A FORTRAN PROGRAM FOR LOCATING AND FITTING PEAKS IN SEMICONDUCTOR DETECTOR SPECTRA
}

W. C. Schick, Jr.

\author{
Ames Laboratory, ERDA \\ lowa State University \\ Ames, lowa 50010
}

Date Transmitted: June 1975

\section{PREPARED FOR THE U. S. ENERGY RESEARCH AND DEVELOPMENT ADMINISTRATION DHVISION OF RESEARCH UNDER CONTRACT NO. W-7405-eng-82}

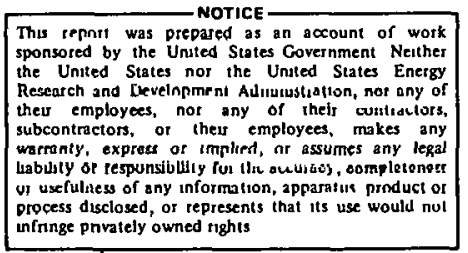


This report was prepared as an account of work sponsored by the United States Government. Neither the United States nor the United States Energy Research and Development Administration, nor any of their employees, nor any of their contractors, subcontractors, or their employees, makes any warranty, express or implied, or assumes any legal liability or responsibility for the accuracy, completeness, or usefulness of any information, apparatus, product or process disclosed, or represents that its use would not infringe privately owned rights.

Available from: National Terhnical Information Service U. S. Department of Commerce P.O. Box 1553 Springfield, VA 22161

Price: Microfiche $\$ 2.25$ 


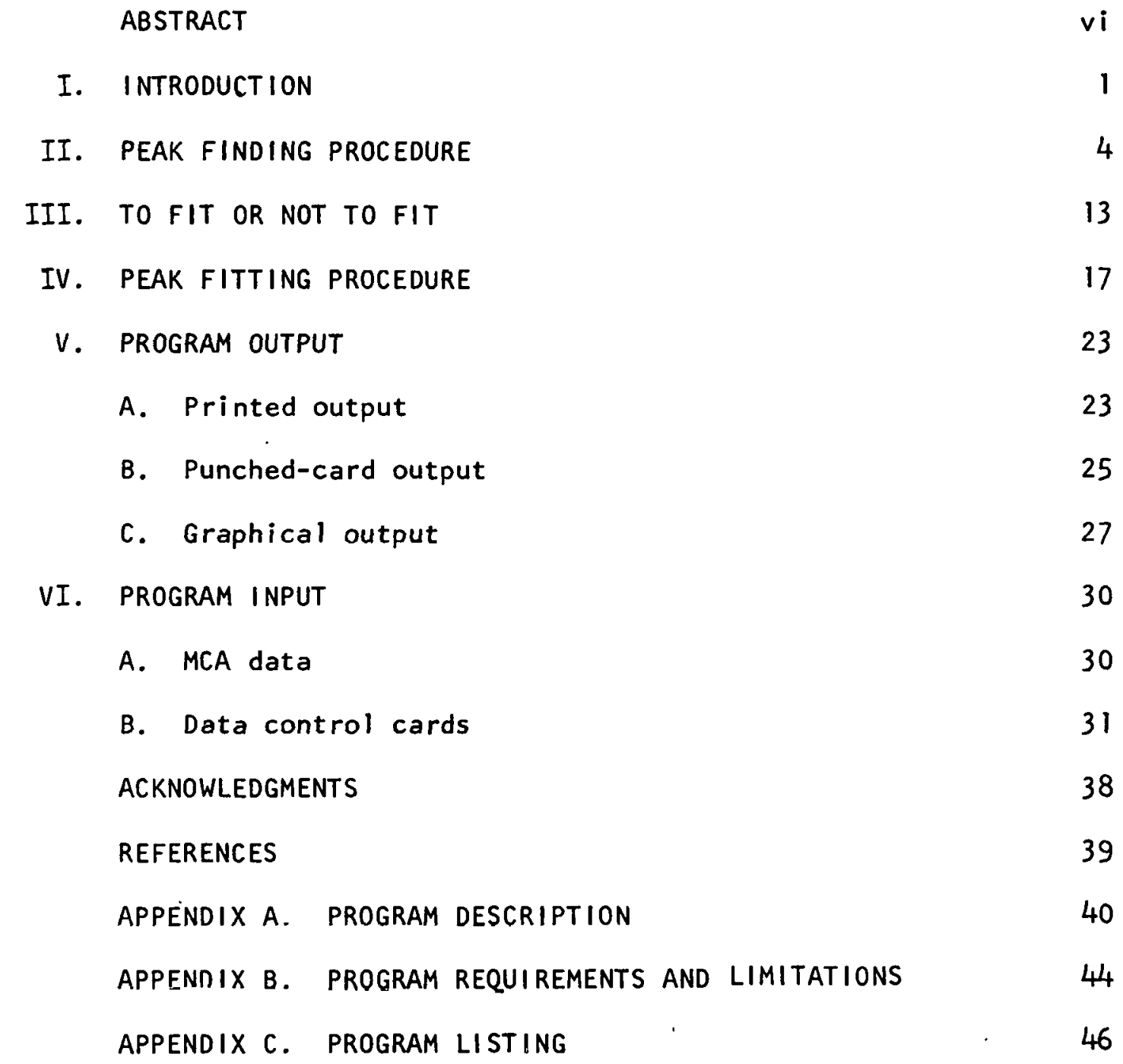


Page

1. The shape of the smoothed second derivative in the vicinity of a Gaussian peak. The dashed line indicates the statistical uncertainty in the second derivative.

2. Typical gamma-ray spectrum showing peaks identified by PEAKFIND when default options were used. Vertical scale is proportional to the square root of the number of counts.

3. Preliminary output provided by PEAKFINO for the spectrum of Fig. 2, indicating the peaks found and the grouping of these peaks into multiplets.

4. Function used for peak fitting.

5. Typical output for one fit, which includes peaks 21 and 22 of Figs. 2 and 3.

6. Summary output for fits performed as indicated in Fig. 3 .

7. Graphical output for fit 3 of Fig. 6 (peak 5 of Figs. 2 and 3).

8. Graphical output for fit 9 of Fig. 6 (peaks 21 and 22 of Figs. 2 and 3 ). Output from this fit is also shown in Fig. 5 .

9. Typical data deck, showing the control cards which produced the output shown in Figs. $3,5,6,7$, and 8 .

10. Overall flow chart for PEAKFIND. The subprograms in which the various operations are performed are indicated in brackets on the right.

11. Flow chart for subroutine PKFIND. 
LIST OF TABLES

\begin{abstract}
Page
I. Format of data control card A. 34

II. Format of data control card C. 35

III. Format of data control card D. 37
\end{abstract}




\section{ABSTRACT}

A FORTRAN program is described which locates peaks in semiconductor detector spectra and then fits a skewed-Gaussian line shape to certain of these peaks to determine centroids, areas, and peak shape parameters. The user may adjust the strictness of criteria used in the peak location procedure to permit the identification of virtually anything that might possibly be a peak, or he may specify that only well-defined peaks are to be found. An estimate is made of the centroid, energy, and intensity (corrected for the energy dependence of the detector efficiency) for each peak found. Fitting is then performed only where the estimated peak intensity exceeds a lower limit specified by the user. Alternatively, the user may specify which specific peaks he wishes to have fitted. The nonlinear least-squares fitting method is a modification of the procedure used in the companion program SKEWGAUS. PEAKFIND normally requires the user to supply only four input data cards for the analysis of a whole multichannel analyzer spectrum, and if default options are chosen for most parameters these cards will be largely blank. 
$v i \mathbf{i}$

DISTRIBUTION LIST

W. C. Schick

50

W. L. Talbert 50

Ames Laboratory Library $\quad 10$

ERDA-COO I I

ERDA-TIC

$\begin{array}{ll}\text { TOTAL } & 138\end{array}$ 


\section{INTRODUCTION}

PEAKFIND is a FORTRAN program used for finding and fitting peaks in multichannel analyzer (MCA) spectra obtained with semiconductor detectors. It first locates the peaks that are present in a spectrum and estimates their centroids and areas. It then fits an analytic function to the channels in the vicinity of certain of these peaks to determine (among other things) accurate centroids and areas. These centrolds and areas may then be used by another program to determine transition energies and intensities.

The peak finding procedure is based on the method of Mariscotti. It employs an examination of the smoothed second difference between adjacent channels in the MCA spectrum to locate the peaks. The criteria for identifying a peak have deliberately been made very loose, so that the program can be instructed to find virtually everything that might possibly be a peak (except where adjacent peaks are not resolved from each other). The user may adjust both the amount of smoothing and the tightness of the main peak identification criterion if he wishes to change the balance between the probability of missing real peaks on one hand, and of finding statistical fluctuations that are not real peaks on the other hand. The design of PEAKFIND is based on the assumptlun that the usor will consider the missing of real peaks to be a far more serious problem than the finding of spurious peaks. Since any spurious peaks found by the program will usually be very weak, the user may discriminate against them by specifying that only the more intense peaks are to be fitted. This allows the computer to avoid the wasting of time in attempting to fit statistical fluctuations or other spurious features, while at the same time the user is still alerted to the existence of features which might perhaps be real peaks. On a subsequent 
execution of the program with the same MCA spectrum the user may specify which specific peaks he wishes to have fitted. This makes it possible to fit the weaker real peaks in the spectrum without wasting time refitting the stronger peaks.

The fitting procedure is very similar to that used in program SKEWGAUS. ${ }^{2}$ The fitting function is a Gaussian to which an exponential tail has been smoothly joined on the lower side. There are up to four variable parameters per peak: the height, the centroid, the full width at half maximum (FWHM), and a parameter ( $\tau$ ) which is the distance from the centroid to the junction point between the Gaussian and exponential functions. The latter two parameters may or may not be variable, depending on the intensity of the peak. If the separation between adjacent peaks is sufficiently small, they will be fit together as (part of) a multiplet. Multiplets with as many as nine component peaks can be handled. The background under the peaks is assumed to be linear.

of course, no program is likely to recognize the separate existence of peaks which are totally unresolved from each other. For such cases it is necessary to use a different program (such as SKEWGAUS) which permits the user to provide input data for each fit to be performed -- in contrast to PEAKFIND, for which the user supplies input data only for the whole spectrum. SKEWGAUS may also prove useful where options are needed which cannot readily be provided in PEAKFIND. These options include the availability of three additional shape parameters per peak, the ability to constrain parameters of different peaks to maintain a fixed ratio during the fitting procedure, the use of a quadratic background, the opportunity to specify which channels are to be fit and to include gaps in the fitting 
region, and other features. The greater flexibility of SKEWGAUS is achieved, however, at some cost in convenience: The user must determine for himself approximately where the peaks are located, and must supply some input data for each peak to be fit; PEAKFIND, on the other hand, requires the user to supply only four simple input data cards for the whole spectrum (which will be largely blank if the user has selected default input options), and the computer does the rest.

The author has found from experience that, for relatively simple spectra where no unresolved multiplets are present, PEAKFIND is usually adequate to perform all the fitting that is necessary. Where there are unresolved multiplets, or where more preclse fitting is required, it is still very helpful to perform preliminary analysis with PEAKFIND and to leave only the "problem" fits to SKEWGAUS.

PEAKFIND can handle MCA spectra with as many as 8192 channels. The maximum number of peaks that can be handled at one time is 250 . Any number of MCA spectra may be analyzed in one execution of the program. In addition, it is possible to analyze one MCA spectrum several times, using different parameters or examining different parts of the spectrum each time.

The load module for PEAKFIND, when compiled with the $H$ level FORTRAN compiler, is about $156 \mathrm{ki}$ lobytes long ( $39 \mathrm{~K}$ words) when no overlays are used. A simple overlay structure may be used to permit execution in a 128 kilobyte region of renre storage.

The execution speed of PEAKFIND may be illustrated by the following example: A typical recent execution on the IBM $360 / 65$ system at lowa State University found 139 peaks in an 8192 channel MCA spectrum; performed 13 fits with an average of more than 50 channels in each fit, Involving a 
total of 29 peaks with 84 variable parameters, and requiring a total of 97 iterations; all in 24.3 seconds of CPU time (exclusive of the plot step).

\section{PEAK FINDING PROCEDURE}

The method used in PEAKFIND for locating peaks is a modification of the method of Mariscotti. (Ref. 1 will henceforth be referred to as MAM.)

Let us assume temporarily that the MCA spectrum is a continuous curve, rather than a series of discrete points. The peaks that we wish to locate rise above a background that we shall assume is approximately linear in the vicinity of a peak. This background may be eliminated by taking the second derivative of the curve. The shape of the second derivative in the vicinity of the peak will depend, of course, on the shape of the peak itself; but for any reasonable peak shape, we may assume that the second derivative will be rather strongly negative near the highest point of the peak, becoming positive on either side of the peak and going to zero a short distance away from the peak. A fluctuation of this sort in the second derivative could be taken as the indication of the existence of a peak.

In reality, of coursc, the spectrum consists of discrete points rather than a continuous curve. This suggests the examination of the second difference of the MCA data channels. If there were no statistical fluctuations in the data, the statements of the previous paragraph would continue to be valid, with the phrase "second difference" replacing "second derivative." In fact, however, the statistical fluctuations in the second difference are quite significant. To illustrate, let us call the number of counts in the ith channel $\mathrm{N}_{i}$, and let us assume that the statistical uncertainty in this 
number is $\sqrt{N}_{i}$. The second difference is given by

$$
s_{i}=N_{i+1}-2 N_{i}+N_{i-1}
$$

The statistical uncertainty in $\mathrm{S}_{\mathbf{i}}$ is given by

$$
F_{i}=\sqrt{N_{i+1}+4 N_{i}+N_{i-1}}
$$

Now suppose that we have a peak whose shape is a perfect Gaussian function with a height of 100 counts and a FWHM of 5 channels, rising above a flat background with an average height of 100 counts per channel. Such a peak would be easily recognizable, standing well above the statistical fluctuations in the background. But the value of $S_{i}$ at the centroid of the peak (where the magnitude of $s_{i}$ is greatest) would be -21 counts, while the uncertainty. in this value would, from (2), be more than 34 counts. Thus, the peak might easily be overlooked in a search of $s_{i}$ versus channel number. It follows that some procedure for smoothing the statistical fluctuations is essential if the second difference approach is to be used.

The simplest smoothing technique is to perform an unweighted average of the counts in a group of $w$ adjacent channels centered about a given channel. If this "smoothing window" $w$ is an odd integer, we may set $w=2 m+1$ and write $\quad s^{\prime}{ }_{j}=\sum_{j=i-m}^{i+m} \quad s^{0} j$

where $S^{0}$ is given by (1). (A weighted average would involve dividing the right side of (3) by $w$, but it is not necessary to perform this calculation.) Further smoothing is accomplished by repeating the application of (3), so that the relationship between successive smoothings of the data is

$$
s^{n+1}=\sum_{j=i-m}^{i+m} s_{j}^{n}
$$


where the superscript of $S$ refers to the number of times the smoothing operation has been performed. MAM gives an extensive treatment of the determination of optimum values for the smoothing window, $w$, and the number of smoothings, $z$. The conclusion is drawn that 5 smoothings with $w$ equal to the odd integer closest to $0.6 \times$ FWHM provides the best compromise between the objectives of being able to recognize small isolated peaks on a large background, and being able to recognize both members of closelyspaced doublets.

The experience of the author has indicated that the amount of smoothing is highly important to the success of the program when one is dealing with complicated spectra. Too much smoothing can cause both members of closely-spaced doublets to be missed, while too little smoothing can cause fairly prominent single peaks to be missed if the statistical fluctuations are great enough. Because of this, the restriction of $w$ to odd integers has been found to be undesirable. An even value for $w$ does not readily lend itself for use with equation (3) because of the fact that the values of $j$ cannot be symmetrically placed about $i$. However, this problem can be overcome if the number of smoothings is even. One can easily show Lhat the recursion formula for the reault of two successive smoothings can be written as

$$
s^{n+2}=w s_{i}^{n}+\sum_{j=1}^{w-1}(w-j)\left(s^{n}{ }_{i-j}+s_{i+j}^{n}\right)
$$

This expression is equally valid if $w$ is even or odd. PEAKFIND performs its smoothing by applying (5) twice to the second difference, producing the effect of four smoothings. The default value for $w$ is the integer (odd or even) closest to $0.6 \times$ FWHM. The user may, if he wishes, override the default value for w merely by supplying his own value as part of the input data. 
It is necessary to calculate the statistical uncertainty in $S_{i}$ (we henceforth drop the superscript on $S$ since the number of smoothings is assumed to be 4). Where the number of counts in nearby channels is approximately equal to $N_{i}$, this statistical uncertainty is easily shown to be

$$
F_{i}=\sqrt{\varphi N_{i}}
$$

where $\varphi$ is a constant whose value depends on $w$ and the number of smoothings. MAM has a tabulation of $\varphi$ for odd values of $w$ with $z$ from 1 through 5 . For $z=4$ as used in PEAKFIND, the values of $\varphi$ are $6,28,82,184,350,596 \ldots$ for $w=1,2,3,4,5,6 \ldots$, respectively.

In the vicinity of a peak, it is to be expected that $S$ will have a form similar to that shown in Fig. 1. Here, $i_{1}$ and $i_{2}$ are the first and last channels in which $s_{i}$ is greater than $i$ ts statistical uncertainty $F_{i}$; $i_{3}$ and $i_{5}$ are the first and last channels in which $s_{i}$ is negative; and $i_{4}$ is the channel in which $S_{i}$ has its maximum negative value. MAM contains a detailed theoretical investigation of the relationships to be expected among these channels under the assumption of a Gaussian peak shape. This investigation leads to the assignment of four conditions for the identification of a peak, based on (a) the magnitude of $s_{i}$ at $i_{4}$, (b) the width of the region between $i_{3}$ and $i_{5}$, (c) the separation of channels $i_{2}$ and $i_{3}$, and (d) the width of the region between $i_{1}$ and $i_{2}$. These rather stringent conditions were established in MAM to prevent the mistaken identification of Compton edges, statistical fluctuations, or other spurious features as peaks.

The author's experience with the conditions of MAM have led him to the conclusion that they are far too restrictive for the purposes for which PEAKFIND is intended, in that they cause too many real peaks to be 


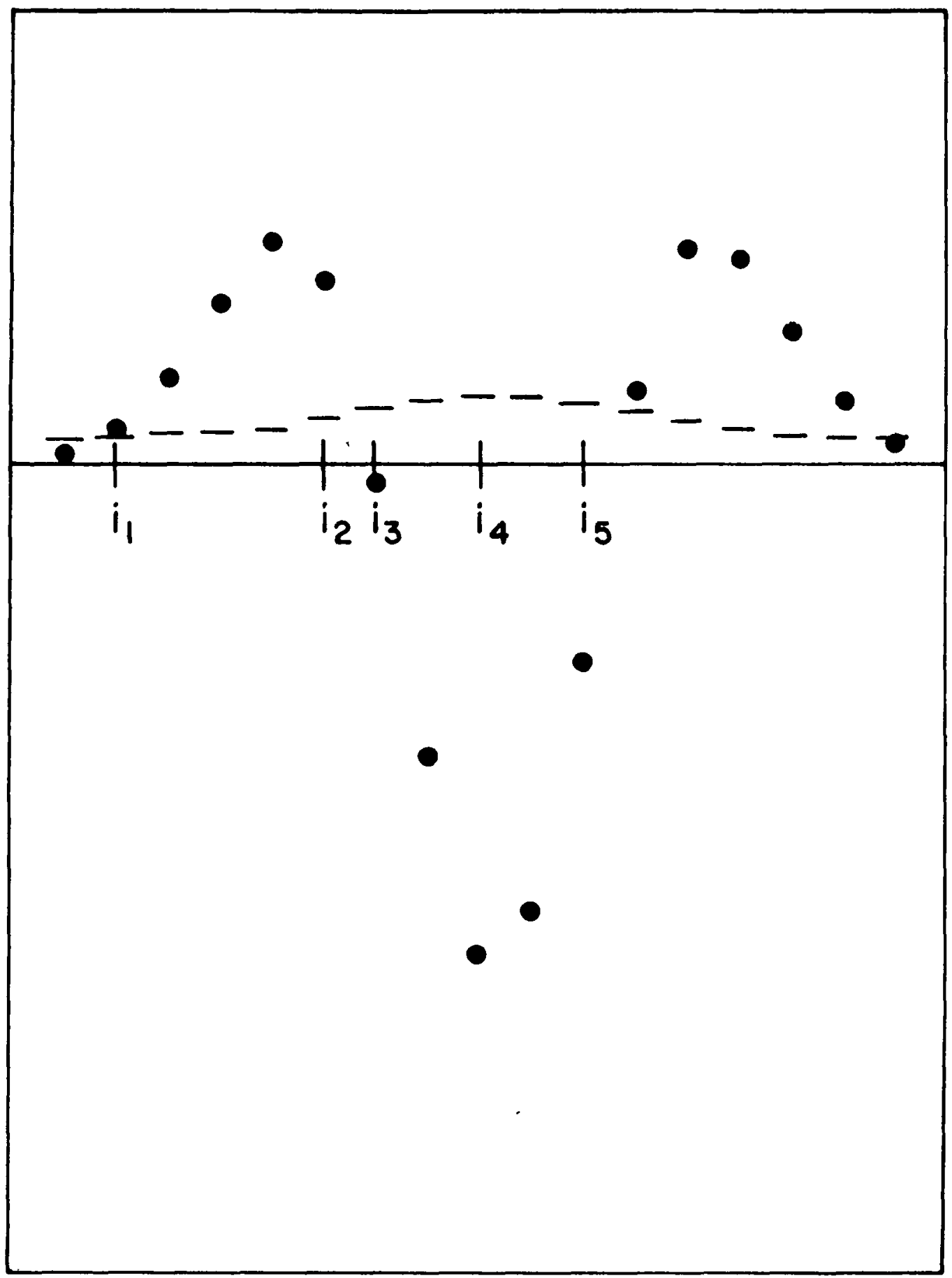

Fig. 1. The shape of the smoothed second derivative in the vicinity of a Gaussian peak. The dashed line indicates the statistical uncertainty in the second derivative. 
missed (especially in complicated spectra). Condition (d) frequently causes the upper component of a partially resolved doublet to be missed, and the lower component may be missed as well if it is smaller than the upper component, due to condition (b). Condition (d) can also prevent the identification of moderately weak peaks that happen to have large statistical fluctuations.

In an attempt to correct these problems, an entirely different set of conditions for recognizing peaks was adopted in PEAKFIND. These conditions were determined from experience rather than from theoretical considerations. It was found that any test on the region from $i_{1}$ to $i_{3}$ in Fig. 1 tends to cause real peaks to be missed, especially in partially resolved multiplets. Thereforc, it was decided to test only on the region from $i_{3}$ to $i_{5}$. The following condltlons were established:

1. The region from $i_{3}$ to $i_{5}$ must be at least $w+1$ channels wide and not greater than $3 \times$ FWHM channels wide.

2. The sum of the values of $s_{i}$ between $i_{3}$ and $i_{5}$ inclusive must be great enough to satisfy inequality (7) where $C$ (the peak $i_{5}$ limit parameter) is a constant whose default value is 2.0 . $\sum_{i=i_{3}} \quad s_{i}>C \times w \times F_{i_{3}}$

The first condition tends to prevent the mistaken identification of either narrow statistical fluctuations or broad features such as compton edges and backscatter peaks. The second condition effectively determines the smallest peak that can be found by the program. It seems more reasonable, from statistical considerations, to base this condition on the total area of the negative region of $s_{i}$ rather than on the height, as is done in MAM. These conditions are sufficiently loose that PEAKFIND will occasionally find spurious features that are not real peaks. This generally presents no 
problem since the spurious peaks may easily be rejected before fitting is performed, as described in the following section. However, the user may, if he wishes, reduce the tendency to find such spurous peaks by increasing the value of $C$ in condition 2, but at some cost in the likelihood of missing real peaks that he is interested in.

Fig. 2 shows a portion of a typical gamma-ray spectrum of the sort with which PEAKFIND is commonly used, indicating the peaks that were found when the default options for $w$ and $C$ were chosen. The peak width is about 4.6 channels here, so the default value for $w$ is 3 channels. The default value for $C$ is always 2.0. The vertical scale in this figure is proportional to the square root of the number of counts. On such a plot the statistical error bars are approximately constant in length, and it is these error bars that are plotted in Fig. 2 .

It will be noted that peak 7 in the figure is actually a Compton edge, and the existence of peaks 10 and 12 is open to question. All the other peaks, however, are almost certainly real. If the peak limit parameter $C$ is raised to 3.0 , the program does not find peaks 7,10 , and 12 , but it does find all the other nineteen peaks. On the other hand, it may be observed that the program has failed to recognize that peak 6 is an unresolved doulilet, that there is a weak component on the upper side of peak 9, and that there is an additional component below peak 14 and one above peak 15 . Nothing can be done in PEAKFIND with peaks 6 and 9 , but the additional components next to peaks 14 and 15 are found if the window width $w$ is lowered to 2 while $C$ is kept at its default value of 2.0. This combination of parameters also finds peak 12 to be a doublet, and finds two additional peaks (at channels 1157 and 1216) which are probably not real. However, the Compton edge near channel 970 is not mistaken for a peak when the combination $w=3, c=2.0$ is used. 


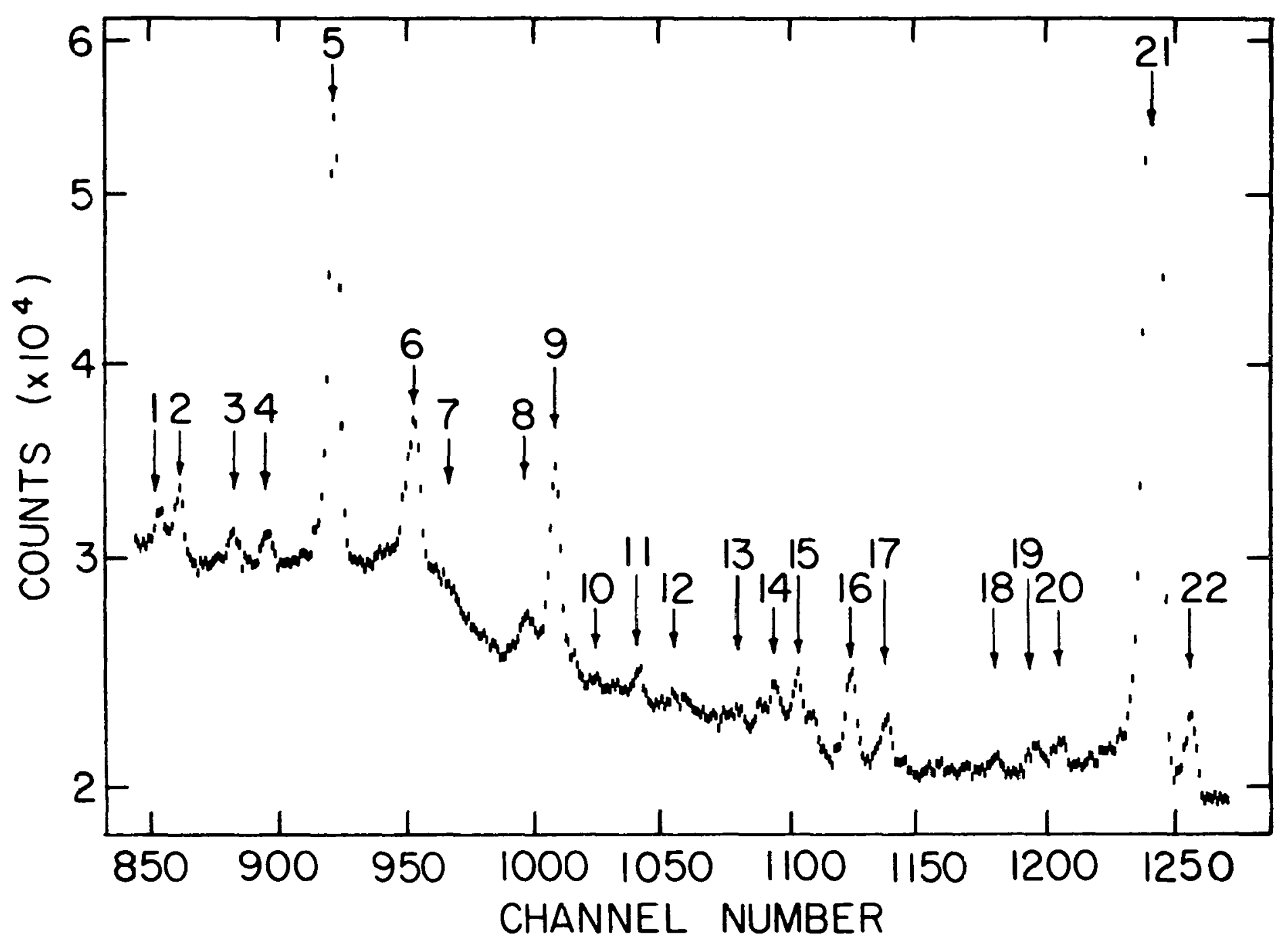

Fig. 2. Typical gamma-ray spectrum showing peaks identified by PEAKFIND when default options were used. Vertical scale is proportional to the square root of the number of counts. 
This example should serve to illustrate the effectiveness of PEAKFIND in locating peaks, and also the ways that the program parameters may be adjusted to suit the user's requirements. This is an example taken from actual practice -- the spectrum of which Fig. 2 is a part was analyzed during a study of the decay properties of 64 -second ${ }^{140} \mathrm{Cs} .3$

After a peak has been found, an estimate is made of its centroid and area from the smoothed second difference. The centroid of $S_{i}$ in the region between $i_{3}$ and $i_{5}$ is used as the estimate of the peak centroid. This estimate usually proves to be quite accurate, rarely being in error by more than a few tenths of a channel for reasonably well resolved peaks. The centroid is converted into a peak energy using a linear calibration of channel number versus energy, supplied by the user.

The peak area is assumed to be proportional to the area of the negative region of $S_{i}$. The latter area is divided by an approximate value for the efficiency of the detector, and then normalized using a value of 100 for the intensity of the strongest peak found. The detector efficiency is assumed to be represented by a straight line on a full logarithmic plot of efficiency versus energy, except at low energies where the straight line smoothly joins a concave-downward parabola. The efficiency curve is delermined by only two parameters that may be supplied by the user -- the slope of the line giving $\log _{10}$ (efficiency) versus $\log _{10}$ (energy), and the energy at which the efficiency curve is a maximum. The default values supplied by the program for these parameters are 1.0 for the slope and $0.1 \mathrm{MeV}$ for the energy of maximum efficiency. These are reasonable values for a moderate-sized coaxial Ge(Li) detector. 
The intensity estimates obtained in this fashion are not, of course, expected to be extremely accurate. They are merely intended to aid the user in identifying the individual peaks and to provide a basis for deciding whether a peak is intense enough to be fitted. Experience has shown that the estimates are generally well within a factor of two of the correct values for reasonably well-defined peaks.

In the foregoing section, the FWHM has been treated as if it were constant throughout the whole spectrum. In fact, however, the peak widths usually increase with increasing energy. It is not feasible to permit FWHM to vary in the peak finding procedure. On the other hand, there is no problem in taking into account the variation of FWHM with peak energy when the fitting is performed. This is accomplished by permitting the user to supply, as part of his input data, the intercept and slope of a straight line giving FWHM as a function of energy. While the peak search is being performed, a unique value of FWHM is used by the program -- the value appropriate for a peak precisely at the center of the region being searched. After the peaks are found, each is assigned the FWHM value appropriate for its energy.

\section{TO FIT OR NOT IU FIT}

Before performing a fit to a peak, it is necessary to establish whether the peak is sufficiently well separated from nearby peaks to allow it to be fitted singly, or whether it must be included with other peaks as part of a multiplet. This decision is based on the FWHM of the peak, as obtained from the straight line supplied by the user giving FWHM as a function of energy. If the separation between two adjacent peaks is less than some constant times FWHM (the default value of this constant being 4.0 ), they 
will be fitted together as (part of) a multiplet. Up to nine peaks may be included in one multiplet. The fitting region will extend below the centroid of the lowest peak a number of channels equal to a constant (default value, 3.0) times the FWHM of the lowest peak, and above the centroid of the highest peak a distance equal to another constant (default value, 2.5) times the FWHM of the highest peak.

It is to be expected that the user will not normally wish to fit all the peaks that have been found. Since the existence of many of the weaker peaks is often questionable, one may wish to specify that only the more intense peaks are to be fitted. Since each peak has been given an intensity estimate, it is possible to specify that only those peaks whose intensity exceeds some cutoff value shall be fitted. The default value for this cutoff is 2.0 (relative to 100 for the most intense peak), but this default value is often overridden in practice. In a multiplet fit, fitting will be performed if any component peak has an intensity exceeding the cutoff value.

A second intensity cutoff value is provided to make it possible to determine those peaks for which the FWHM is to be considered a variable fitting parameter. Since the shapes of the weak peaks are often poorly defined, it is desirable to fix FWHM for these peaks to the straight line values determined from the input supplied by the user. For the stronger peaks whose intensity exceeds the FWHM cutoff, the straight line values of FWHM will be treated only as initial estimates; the "best" values will be determined by the fit. The default value for the FWHM intensity cutoff is 5.0. If the user overrides this default by specifying a value greater than 100, then (since no peak has an intensity greater than 100) all peaks will have fixed FWHM's. 
The peak shape parameter $\tau$ is treated in a manner similar to FWHM. The user supplies the slope and intercept of a line giving $T$ as a function of energy (or accepts default values, as described in the following section). A value of $T$ is assigned to each peak from the straight line. This value is considered to be fixed for any peak whose intensity is less than the $\tau$ cutoff, and is treated as an initial fitting estimate for a more intense peak. The default value for the $\tau$ cutoff is 10 . By overriding with a value greater than 100, the user may fix the $\tau^{\prime} s$ of all peaks.

Before any fitting is attempted, the program provides printed output giving a list of the peaks found with their estimated energies and intensities, as illustrated in the upper part of Fig. 3. Starred peaks are those whose intensities exceed the fit cutoff value. Next, output is provided to indicate how these peaks are grouped into multiplet fits, as illustrated in the lower part of Fig. 3. This list includes the number of peaks in each multiplet, the energy of the first peak of the multiplet, the first and last channels in the fitting region, the initial estimates of FWHM and $\tau$ for the first peak, and the centroids of all peaks in the multiplet. The output illustrated in Fig. 3 was obtained from an analysis of the spectrum of Fig. 2, using default values for all parameters except the energy calibration and FWHM.

At this point, the user has three options on how to proceed. The options are determined by the value of the index IFIT.

IFIT $=0$ : No fitting will be attempted. The user wishes to examine the output already provided before proceeding further.

IFIT = 1: Fitting will be attempted for all multiplets in which at least one component peak has an intensity greater than the fit cutoff value. 


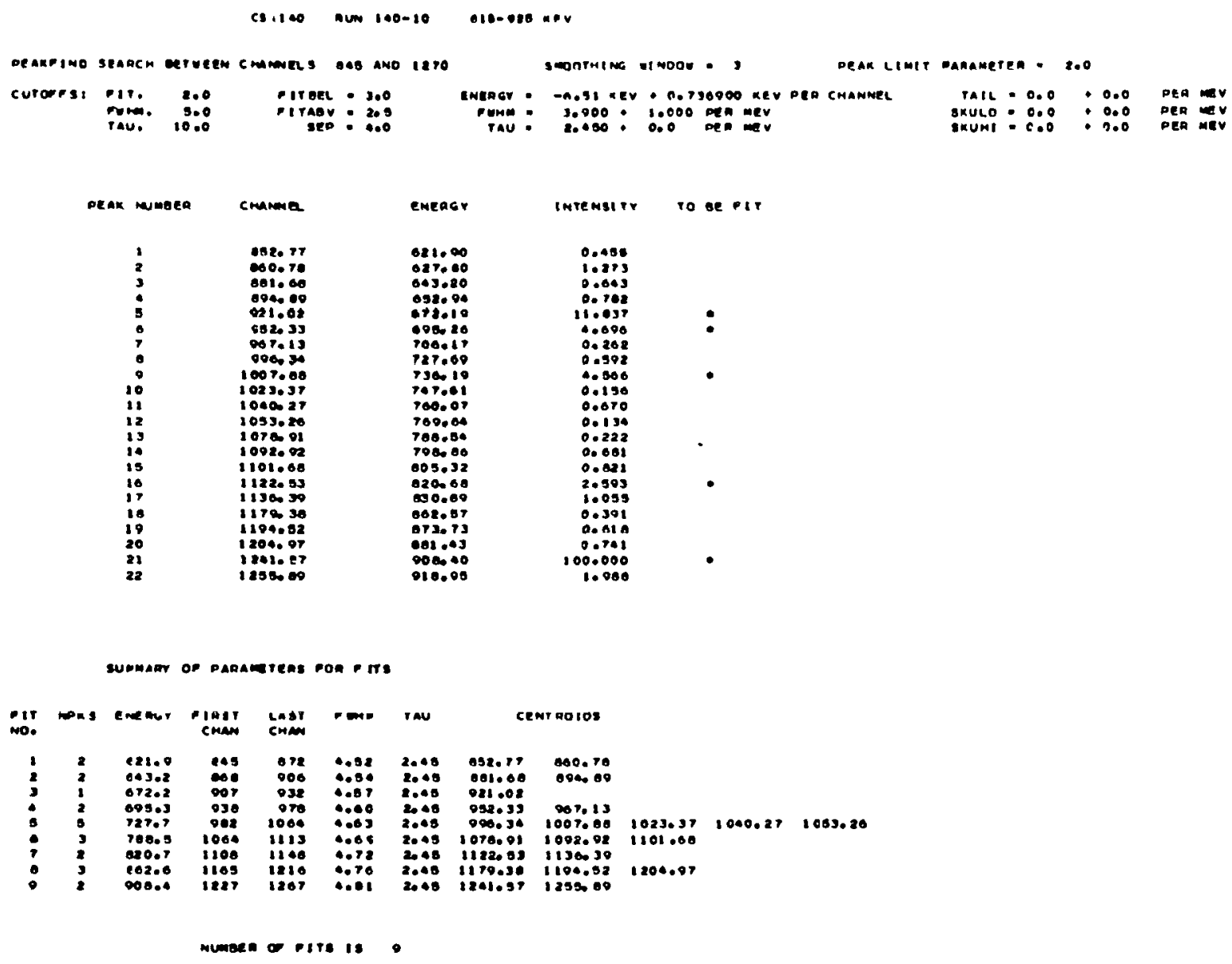

Fig. 3. Preliminary output provided by PEAKFIND for the spectrum of Fig. 2, indicating the peaks found and the grouping of these peaks into multiplets. 
IFIT $=2$ : Fitting will be attempted for those specific multiplets designated by the user. Multiplets are identified by the fit number as given in the first column of the lower part of Fig. 3.

The last option is useful primarily for fitting selected weaker peaks in a spectrum whose stronger peaks have already been fitted on previous executions of PEAKFIND with IFIT $=1$. Obviously, the user cannot know the numbers of the multiplets he wishes to fit unless he has previously obtained a listing similar to that shown in Fig. 3. Furthermore, it is necessary that most of the input parameters remain unchanged between executions in order to guarantee that exactly the same peaks will be found and that they will be grouped into multiplets in exactly the same way. However, those parameters that do not affect the finding or grouping of peaks (notably the cutoff and $\tau$ parameters) may safely be changed without affecting the multiplet identification.

\section{PEAK FITTING PROCEDURE}

The peak fitting procedure is very similar to that used in program SKEWGAUS, and the reader is directed to Ref. 2 for complete details. Only a brief summary is given here.

The fitting function is a Gaussian to which a simple exponential function has been smoothly joined on its lower side. The four variable parameters are the peak height $h$, the centroid $x_{0}$, the FWHM of the Gaussian, and the distance $T$ (in channels) from the centroid to the junction point. These parameters are illustrated in Fig. 4. The height and centroid are always treated as variable fitting parameters, but FWHM and $T$ are variable only for those peaks whose intensity estimates exceed the corresponding cutoff values, as explained in the previous section. 


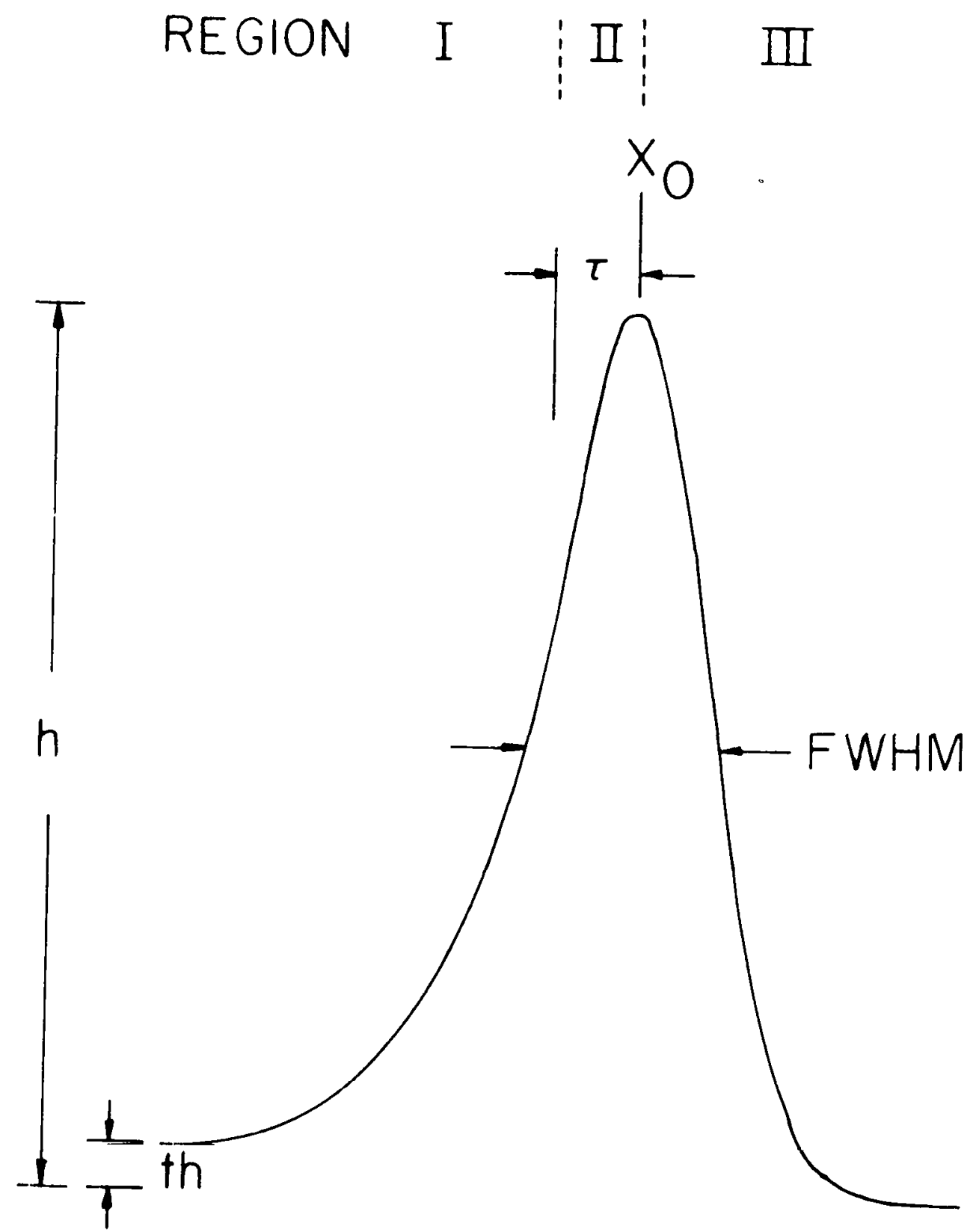

Fig. 4. Function used for peak fitting. 
The fitting function used in SKEWGAUS includes three additional variable parameters which permit a wider variety of peak shapes to be fit. These additional parameters are the tail parameter ( $t$ in Fig. 4), which permits the fitting function to approach a constant value other than zero on its lower side; the lower skewness parameter, which permits some additional skewing of the lower side of the peak; and the upper skewness parameter, which provides for skewing on the upper side of the peak. These three are not available as variable parameters in PEAKFIND; however, provision has been made for the user to supply fixed values for these parameters for each peak. This is accomplished, as with FWHM and $T$, by supplying the intercept and slope of a straight line giving the value of each parameter as a function of peak energy.

The background in PEAKFIND fits is a straight line given by the expression

$$
f_{B}=A+8\left(x-x_{1}\right)
$$

where $x$ is channel number and $x_{1}$ is the number of the first channel in the fitting region. The use of a more complicated function allowing for curvature in the background has been found from experience to be undesirable, causing more problems than it solves. If a curved background is clearly called for, SKEWGAUS should be used.

Fitting is accomplished by the standard nonlinear least-squares (NLLS) method. The quantity

$$
Q=\sum_{i} w_{i}\left(N_{i}-f_{i}\right)^{2}
$$

is minimized by an iterative process. Here, $N_{i}$ is the number of counts in the $i$ th channel, $f_{i}$ is the fitting function evaluated at the $i$ th channel, and $w_{i}$ is a weight associated with the error in $N_{1}$. The weight $w_{i}$ is given by 
the following expression:

$$
w_{i}=1 /\left[N_{i}\left(1-c+d^{2} N_{i}\right)+c N_{m}\right]
$$

Here, $d$ is the r.m.s. deviation in channel width of the analogue-to-digital convertor of the MCA (i.e., the differential nonlinearity). $\mathrm{N}_{\mathrm{m}}$ is the maximum number of counts among the channels included in the fit. The constant c is included for the purpose of reducing somewhat the very large weight that would otherwise be given to channels with a small number of counts, where $N_{i}$ is very small compared with $N_{m}$. The values of $c$ and $d$ built into the program are 0.02 and 0.005 , respectively, but they may easily be changed if desired. Setting $c$ and $d$ both equal to zero will give standard statistical weighting.

$Q$ is minimized by solving the set of nonlinear equations

$$
\partial Q / \partial \alpha_{j}=0
$$

where $\alpha_{j}$ represents the $j$ th free parameter in the fitting function. Since equations (11) are not solvable analytically, an iterative procedure is used to get an approximate solution. Initial estimates are supplied for the values of the free parameters, and equations (11) are expanded in powers of small quantities. The nonlinear terms in the expansion are dropped, and the resulting linear equations are solved by the method of matrix inversion. The solution is a set of new (and hopefully better) values for the $\alpha_{j}$, which are then used as estimates in the next iteration.

The iterative procedure continues until one of the following conditions occurs:

(1) All parameters no longer change significantly on successive iterations (normal convergence). A "significant" change is defined to be a fractional change of $10^{-3}$ in $h, 10^{-5}$ in $x_{0}, 10^{-3}$ in FWHM, $5 \times 10^{-3}$ in $\mathrm{T}$, $10^{-4}$ in $A$, and $10^{-4}$ in the quantity $(B+1000)$. 
(2) Q increases on successive iterations, or fails to decrease fractionally by more than $10^{-4}$. The test for this condition is not applied until the twentieth iteration since $Q$ frequently increases on early iterations but subsequently decreases.

(3) The coefficient matrix is singular, so the equations resulting from the linearization of (11) cannot be solved. This usually means that some variable parameter is totally undefined.

(4) Thirty iterations have taken place and none of the above conditions has occurred.

After convergence has been achieved, or the iterative procedure has been stopped without convergence because of conditions (3) or (4), the final value of $Q$ is divided by the number of degrees of freedom (the number of channels in the fit minus the number of variable parameters) to determine the variance of the fit. If only statistical fluctuations affected the quality of the fit, one could distinguish a good fit from a poor one by the requirement that the variance be close to 1.0 for a good fit. In fact, however, there are many non-statistical effects that must be considered, the most important being the fact that the fitting function is an arbitrarily chosen representation of the peak shape. Where the number of counts in a peak is large (say, on the order of $10^{6}$ ), the statistical uncertainties in the data points are small enough to expose the small differences between the fitting function and the actual line shape, with the result that the variance may be significantly greater than 1.0 for a fit that is completely acceptable. On the other hand, a fit to a small multiplet rising above a large background may yield a variance close to 1.0 even if some major error has occurred, such 
as the failure to find all of the components of the multiplet. It follows, then, that the variance alone cannot be relied upon blindly in determining whether a fit is acceptable. Examination of a plot of the fit is strongly recommended.

The uncertainty in the final value of each variable parameter is determined by taking the square root of the product of the appropriate diagonal element of the inverted coefficient matrix times the variance. These uncertainties must be interpreted with some care since they are based on statistical considerations only and do not take into account such non-statistical factors as the imperfect representation of the actual peak shape by the fitting function. Further discussion of the parameter uncertainties (as well as all the other topics covered in this section) may be found in Ref. 2 .

The NLLS method of fitting requires that initial estimates be provided for all variable parameters. The background parameters $A$ and $B$ are initialized as, respectively, the number of counts in the first channel of the fitting region and the slope of a line drawn between the first and last channels of the region. The centroid estimates are provided when the peaks are found, as discussed above. The height of a peak is estimated to be the contents of the centroid channel minus the background contribution to that channel. FWHM and $\tau$, as has been mentioned, are given estimates based on the assumption that these parameters vary linearly with energy. In practice, one simply estimates visually the FWHM for a few of the stronger peaks in the spectrum and fits these values to a straight line. The slope and intercept of this line must be supplied as part of the input data. It is not so easy to estimate $T$ visually, so the user may let the program 
itself determine the initial estimates for $\tau$. Since $\tau$ usually varies quite slowly with energy, the default initial estimate is the same for peaks of all energy, being equal to one-half the FWHM for a $1 \mathrm{MeV}$ peak. After the stronger peaks in a spectrum have been analyzed, the user may wish to use the fitted values of FWHM and $T$ for these peaks to determine the best straight lines giving FWHM and $\tau$ as functions of energy. These straight lines may be used in fitting the weaker peaks. Experience has shown that the assumption of a linear variation of FWHM and $\tau$ with energy is generally quite satisfactory.

\section{PROGRAM OUTPUT \\ A. Printed output}

The preliminary output listing provided after the peaks have been found was discussed above and illustrated in Fig. 3.

A listing of the values of all variable parameters after each iteration of each fit may optionally be provided. A typical listing for one fit is shown in Fig. 5. This fit consists of peaks 21 and 22 of Fig. 2. The parameter values listed under iteration 0 are the initial estimates. The parameters are numbered as follows:

1, height of first peak;

2, centroid of first peak;

3, FWHM of first peak;

4, T of first peak;

5, helght of second peak;

6 , centroid of second peak.

In this example, the intensity estimate for the second peak was sufficiently small that its FWHM and $\tau$ (parameters 7 and 8 ) were not variable and hence 


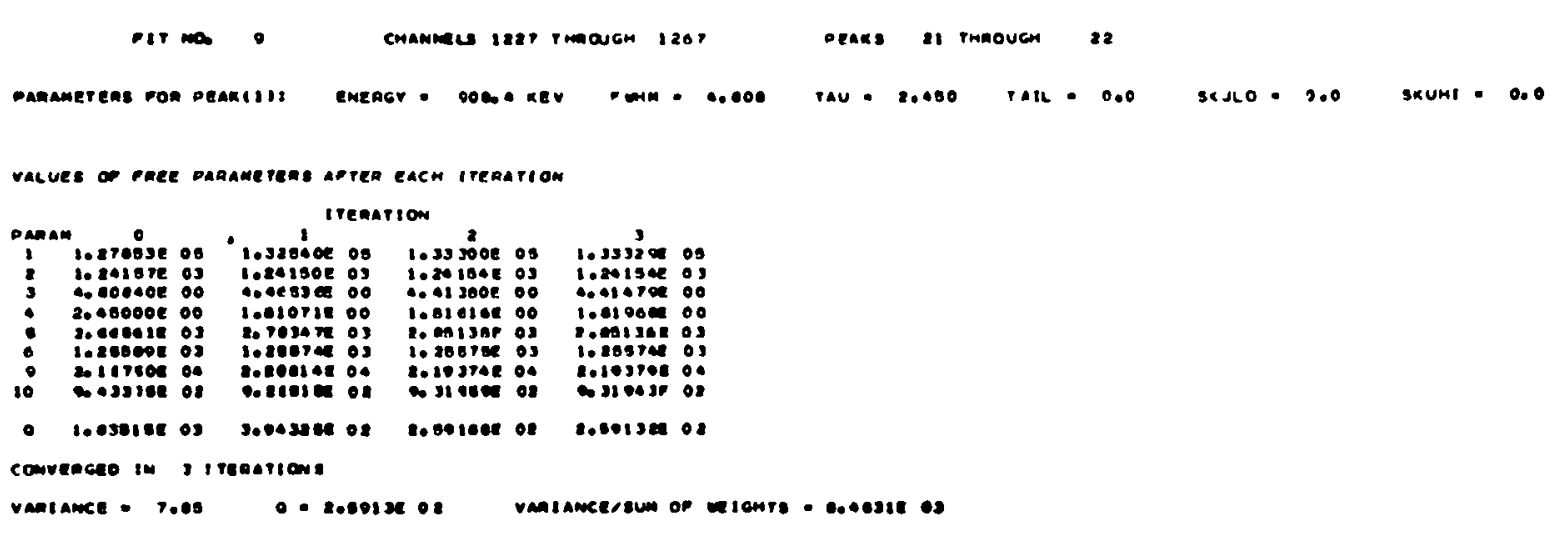

Fig. 5. Typical output for one fit, which includes peaks 21 and 22 of Figs. 2 and 3. 
are not listed. If there were a third peak, its parameters would be numbered 9 through 12, and so on. The next-to-last parameter (number 9 in this example) is always the background height $A$. The last free parameter is the background slope B plus 1000 .

In the example of Fig. 5, convergence is achieved very quickly because the initial estimates are reasonably close to the correct values and the peaks are very well defined. In other cases convergence is not always so rapid.

After all fits have been performed on one MCA spectrum, a summary output of the essential results of the fits is provided. A typical summary output is shown in Fig. 6. The first few columns are the fit number, the number of peaks in the fit, the number of free parameters, the number of channels in the fit, the variance of the fit, and the reason for convergence or non-convergence. The final values of all parameters for the individual peaks follow. An error of 0.0 indicates that the parameter was not variable. The areas are obtained by numerically integrating the fitting function over all the channels included in the fit. The error in the area is a combination of the error in the height and the error in FWHM. Further details concernlng areas may be fuund in Ref. 2 .

This summary output is provided in the same job step as the rest of the program, rather than in a separate job step or a separate job, as is the case for the SKEWGAUS summary output.

B. Punched-card output

Two types of punched-card output may be provided by PEAKFIND. The first type is suitable for input to program SKEWGAUS, and is intended for situations where the fitting done by PEAKFIND is not adequate. One card is 


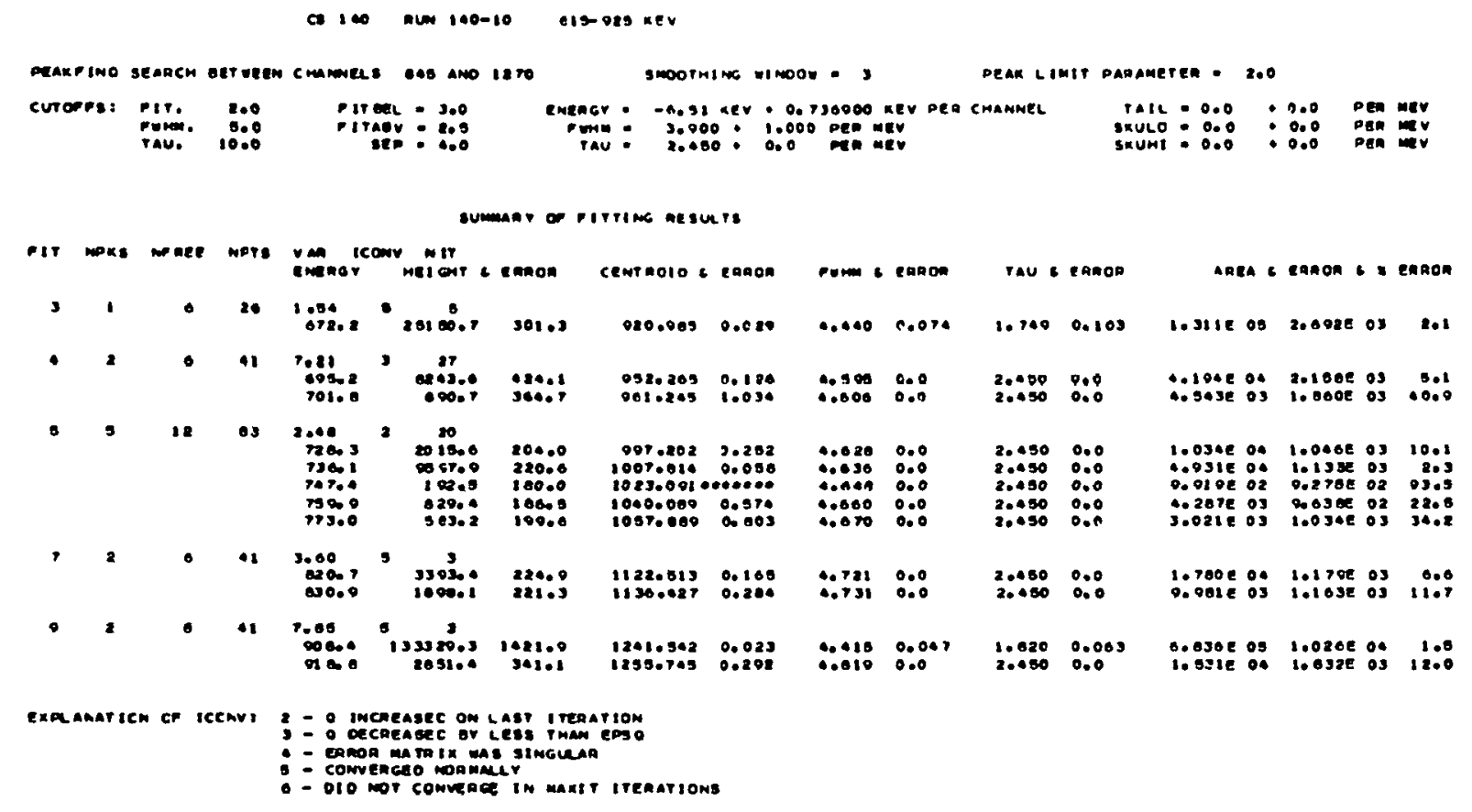

Fig. 6. Summary output for fits performed as indicated in Fig. 3 . 
provided for every fit in the "Summary of Parameters for Fits" (Fig. 3), appropriate for use as data control card D of SKEWGAUS. These cards have the fit number punched in columns 78-80 for identification purposes. In addition, one card is punched for every peak found, in a manner appropriate for use as data control card E of SKEWGAUS.

The second type of punched-card output is intended for use where the results of the PEAKFIND fits are satisfactory, and are to be used to determine accurate energy and intensity values, including corrections for system nonlinearities, detector efficiency variation, and the like. This processing is done by a program called DRUDGE. PEAKFIND will optionally provide punched cards that may be used as input for DRUDGE. There will be one card for each peak that has been fitted, containing the following information: the centroid, the error in the centroid, the area, the height, the error in the height, FWHM, the error in FWHM, $\tau$, and the error in $\tau$. The first five quantities are punched in 10-column fields, the last four quantities in 5-column fields.

Note that these cards for DRUDGE are punched only for those peaks that were actually fitted, while the cards for SKEWGAUS are provided for all peaks found, whether or not any fitting was performed.

\section{Graphical output}

A graph of the results of a fit is an indispensable aid in determining the quality of the fit. Typical plots are shown in Figs. 7 and 8 . It may be observed that the fit in Fig. 8 appears to be quite good, in spite of the fact that the variance of this fit is 7.85 , which would normally be taken to indicate a very poor fit. This is a common situation where the height of the peak is in excess of $10^{5}$ counts, as is the case here. 


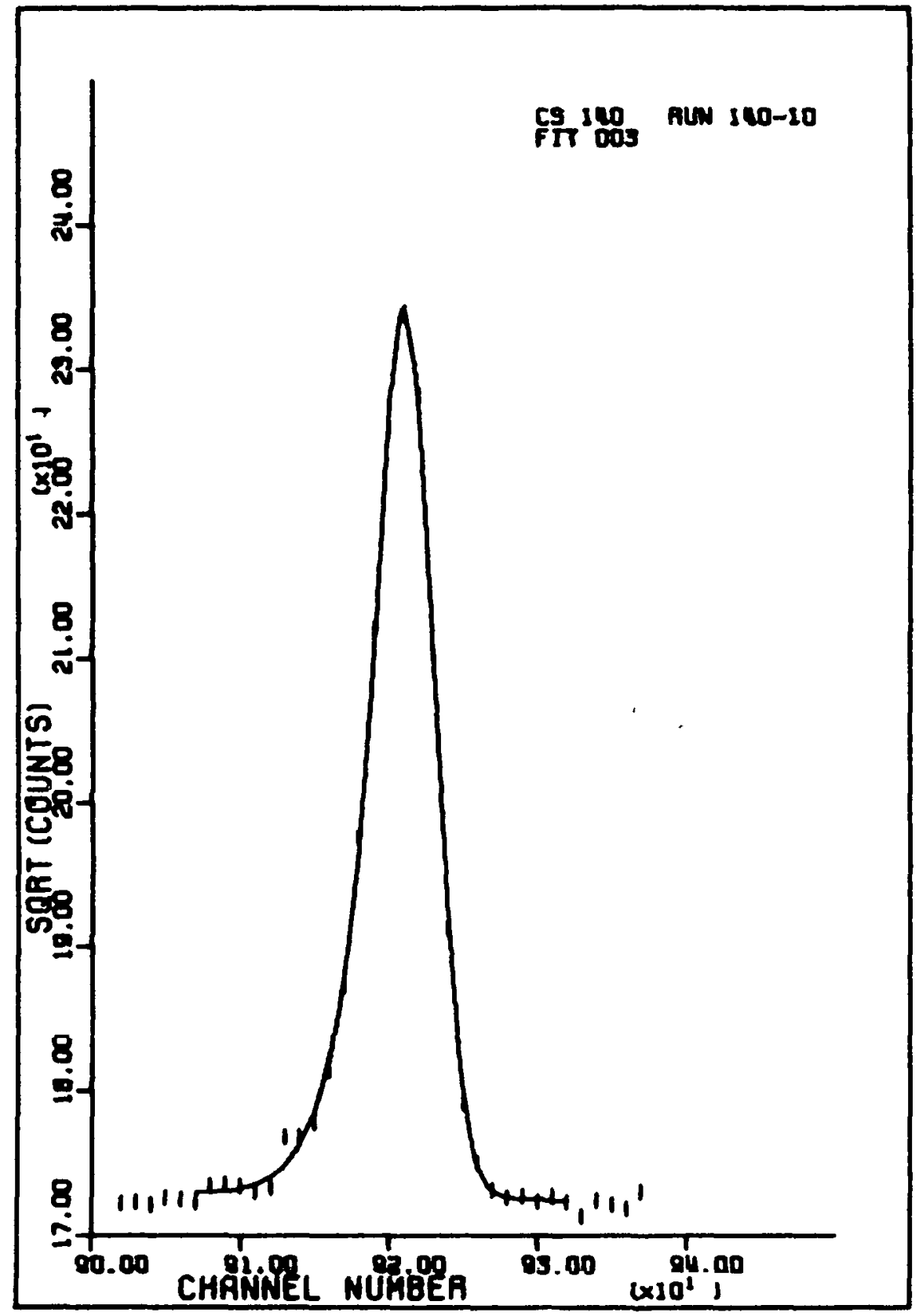

Fig. 7. Graphical output for fit 3 of Fig. 6 (peak 5 of Figs. 2 and 3 ). 


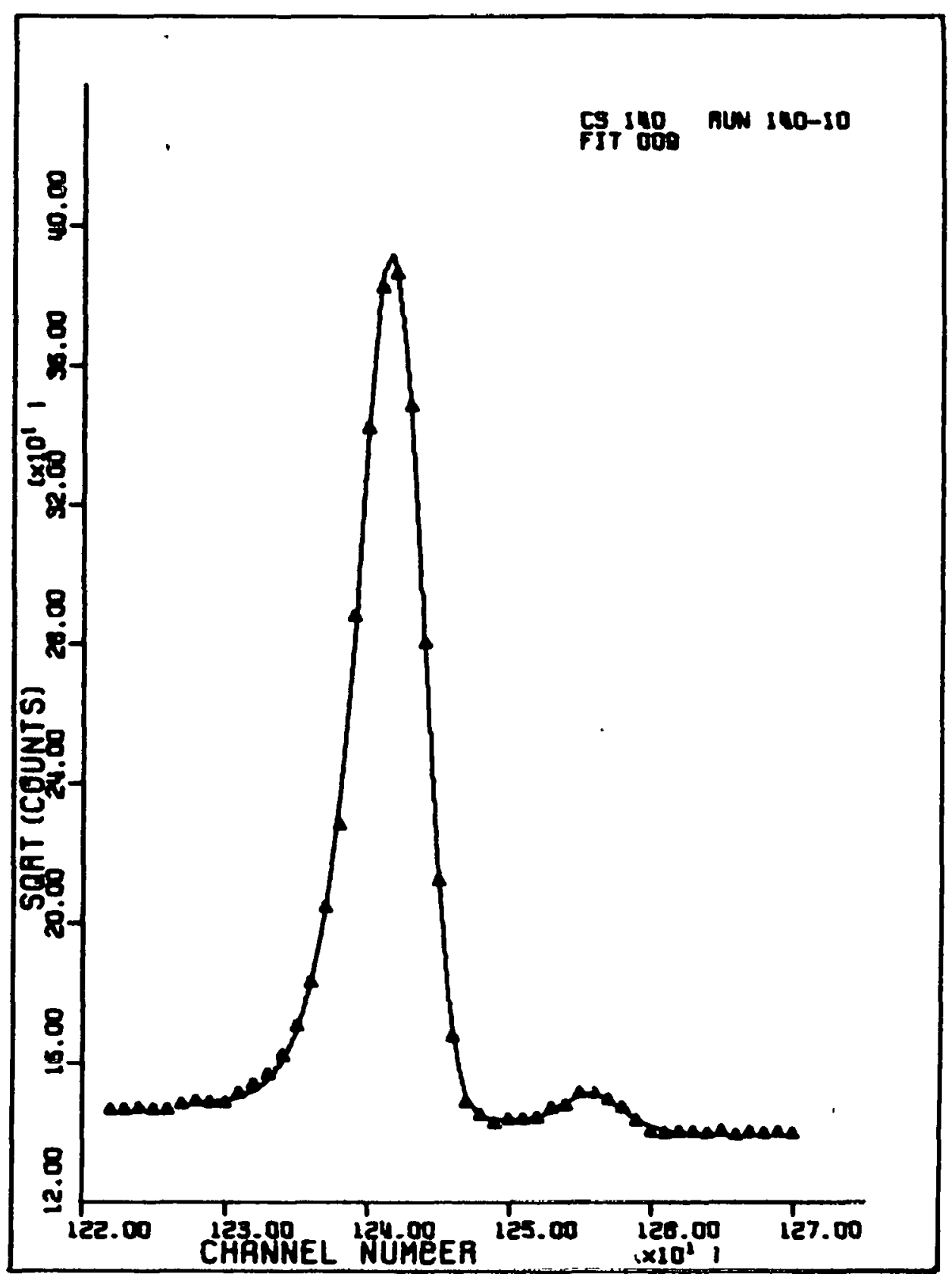

Fig. 8. Graphical output for fit 9 of Fig. 6 (peaks 21 and 22 of Figs. 2 and 3). Uutput from this fit is also shown in Fig. 5. 
The plots are drawn with a constant number of channels per inch (default value, 10). The channels plotted include five additional channels on either side of the fitting region that were not included in the fit. The fitting function is drawn as a smooth curve through only those channels that were actually included in the fit. The vertical scale is the square root of the number of counts. The plotting symbol is normally a vertical line whose length indicates the statistical uncertainty in the number of counts -- an error bar, in effect. If the number of counts is sufficiently large, the size of the error bar becomes too short for convenience. In this event, a triangle (whose size has no significance) is used as the plotting symbol. The graphs are plotted by a Cal-Comp plotter. Most of the work of plotting is done by a set of routines designed locally by $D$. G. Scranton and known as SIMPLOTTER. 4

It must be admitted that not all PEAKFIND fits are as successful as those graphed in Figs. 7 and 8 . Because of the unresolved doublets in the spectrum of Fig. 2, it was necessary, when these data were analyzed during the study of the ${ }^{140} \mathrm{Cs}$ decay scheme, ${ }^{3}$ to resort to SKEWGAUS in order to get acceptable fits for a number of the multiplets.

\section{PROGRAM INPUT}

\section{A. MCA data}

The MCA data may be in several forms -- on cards, magnetic tape, or magnetic disk -- that are appropriate for the MCA's with which this program is generally used. One subprogram, named INPUT, performs the sole function of reading these data. This subprogram is nearly identical with the subprogram of the same name in SKEWGAUS, which is described in detail in Ref. 2. The 
only essential difference is that in PEAKFIND an additional option is provided which permits the reading of the MCA data to be bypassed, so that a given spectrum may be analyzed more than once.

It is assumed that the initial channel of the MCA spectrum being read is channel 0 , not channel 1 (except for data on cards, for which the user may specify the initial channel number).

\section{B. Data control cards}

The input data deck consists basically of four cards for each MCA spectrum. These cards are designated by the letters $A$ through $D$. If the option of fitting specified multiplets (IFIT=2) has been chosen, there will be one or more additional cards, of type E.

Card A specifies the form of the MCA data. The format of this card is given in Table $I$. It is identical to card $A$ of SKEWGAUS, except that an additional option has been provided for variable IREAD.

Card $B$ is a title card on which may appear any 80 characters. These will be printed as the heading of the printed output. In addition, the contents of columns $1-20$ of this card will be the first line of the title on each graph. Card $C$ contains the options for finding and fitting peaks. The format for this card is given in Table II.

Card $D$ contains the energy-dependent quantities. The format for this card is given in Table III.

Card(s) E appears only if IFIT is equal to 2 on card C. A letter $T$ (for "true") will be punched in each column for which the correspondingly numbered multiplet is to be fitted. The numbering of the multiplet fits is given in the first column of the "Summary of Parameters for Fits" (as illustrated in the bottom of Fig. 3). If the number of multiplets is 80 
or less, there will be only one card $E$. If the number of multiplet fits is between 81 and 160, there will be two cards $E$, and so on. The user would specify the fitting of multiplet 81 by punching a $T$ in column 1 of the second card $E$.

After the program has finished with an MCA spectrum it returns to the beginning and reads card $A$ for the next MCA spectrum. Any number of spectra can be handled in a single execution of PEAKFIND. A blank card at the end of the input deck will terminate execution properly. (This blank card is interpreted by the program as card A with IREAD=0.)

The data control cards used to analyze the spectrum of Fig. 2 and to produce the output illustrated in Figs. 3, 5, 6, 7 and 8 are shown in Fig. 9. Default values were accepted for most parameters, as may usually be done in practice. 


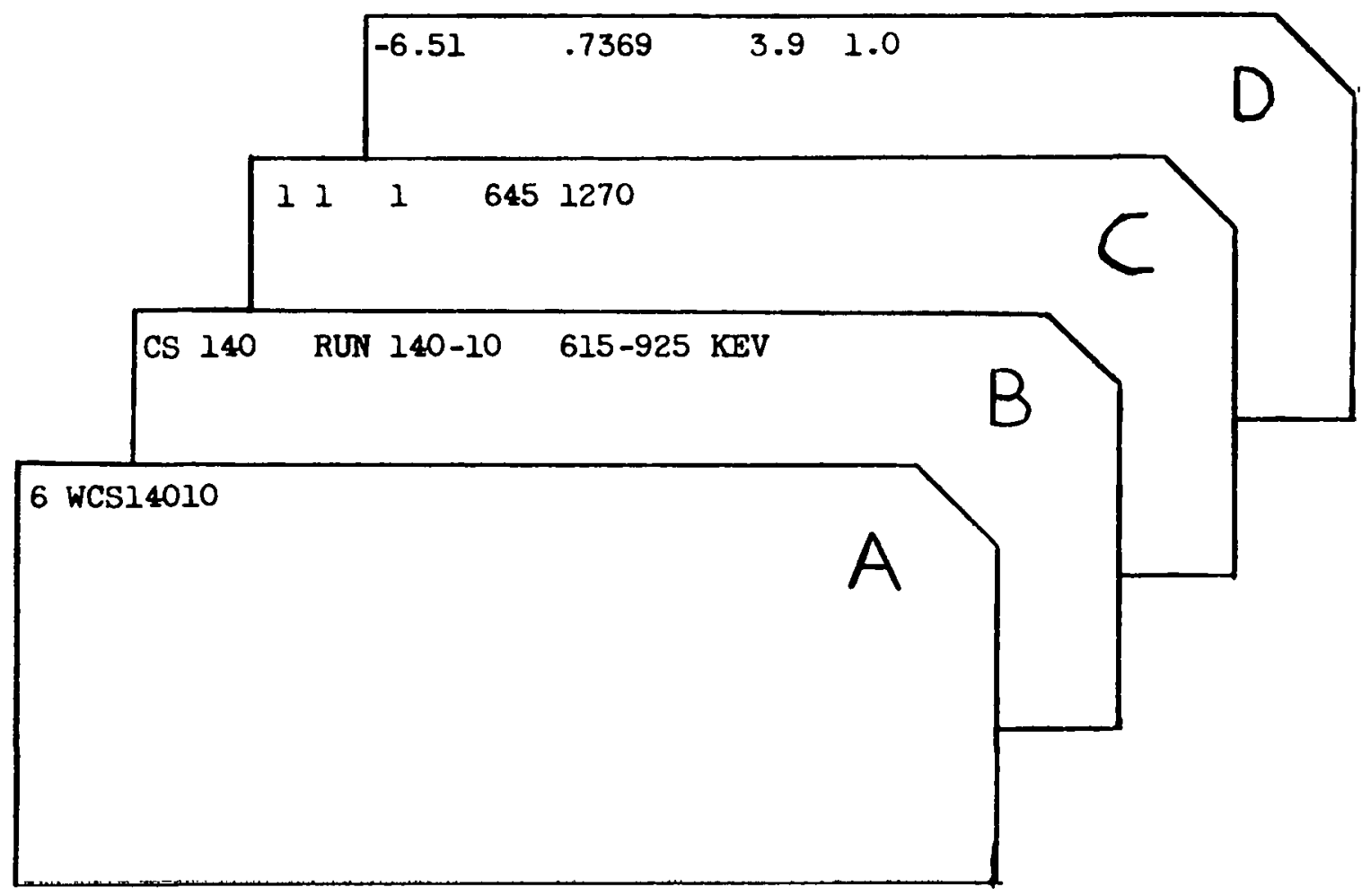

Fig. 9. Typical data deck, showing the control cards which produced the output shown in Figs. $3,5,6,7$, and 8 . 
Table I. Format of data control card A. In this and the following tables, variable names in parentheses have standard default values and hence do not normally need to be supplied by the user.

\begin{tabular}{|c|c|c|c|}
\hline Column & Format & Name & Interpretation \\
\hline 1 & Il & IREAD & $\begin{array}{l}\text { Designates source and format of MCA data. } \\
1 \text { - cards; } 8 F 7.0 \\
2 \text { - cards; 10F7.0 } \\
3 \text { - tape written by GEOS } 4 \mathrm{~K} \text { analyzer; } 3 \mathrm{I} 6,256 \mathrm{~F} 6.0 \\
4 \text { - tape written by TMC 4K analyzer; I6, } 256 \mathrm{~F} 6.0 \\
5 \text { - tape written by TMC I6K analyzer; I6, } 1024 \mathrm{~F} 6.0 \\
6 \text { - disk } \\
7 \text { - no data will be read; processing will } \\
\text { continue on data previously read. } \\
\text { A zero or blank will terminate execution. }\end{array}$ \\
\hline $3-10$ & A8 & IDEN & $\begin{array}{l}\text { Identification word for data on disk. Not } \\
\text { required for data on tape or cards. }\end{array}$ \\
\hline \multirow[t]{2}{*}{$\begin{array}{l}11-15 \\
16-20 \\
21-25 \\
26-30\end{array}$} & $4 I 5$ & $\begin{array}{l}\text { (LOCAT:N) } \\
\text { array }\end{array}$ & $\begin{array}{l}\text { Data on cards: LOCATN ( } 1 \text { ) and LOCATN (2) } \\
\text { are the first and last channel numbers of } \\
\text { the MCA channels to be read in. These data } \\
\text { cards should follow immediately after card A. }\end{array}$ \\
\hline & & & $\begin{array}{l}\text { Data on disk: Not required unless data set } \\
\text { is to be read by position rather than by } \\
\text { identification word. If LOCATN ( } 1) \neq 0 \text {, } \\
\text { array gives location(s) on disk of the data } \\
\text { set to be read. Must also have NTHOUS } \neq 0 \\
\text { in this case. }\end{array}$ \\
\hline $31-35$ & I5 & (NTHOUS) & $\begin{array}{l}\text { Required only if data set on disk is to be } \\
\text { located by position rather than by identi- } \\
\text { fication word. Gives length of data set } \\
\text { in K (units of } 1024 \text { words). }\end{array}$ \\
\hline $36-80$ & -- & -- & $\begin{array}{l}\text { Not referenced by program. May be used to } \\
\text { identify data control deck if desired. }\end{array}$ \\
\hline
\end{tabular}


Table II. Format of data control card C.

\begin{tabular}{|c|c|c|c|}
\hline Column & Format & Name & Interpretation \\
\hline $1-2$ & $\mathrm{I} 2$ & IFIT & $\begin{array}{l}0 \text { - No fitting will be performed. } \\
1 \text { - Multiplets having at least one peak with } \\
\text { intensity greater than FITCTF will be fitted. } \\
2 \text { - Multiplets designated on card(s) E will } \\
\text { be fitted. }\end{array}$ \\
\hline $3-4$ & I2 & IPRINT & $\begin{array}{l}0 \text { - Preliminary and summary printed output } \\
\text { only are provided. } \\
1 \text { - Complete printed output is provided, } \\
\text { including listing similar to Fig. } 5 \text { for } \\
\text { each multiplet. }\end{array}$ \\
\hline $5-6$ & $I 2$ & IPUNCH & $\begin{array}{l}0 \text { - No punched card output. } \\
1 \text { - Punched cards for input to SKEWGAUS } \\
\text { are provided. } \\
2 \text { - Punched cards for input to DRUDGE are } \\
\text { provided. } \\
3 \text { - Punched cards for both SKEWGAUS and DRUDGE } \\
\text { are provided. }\end{array}$ \\
\hline $7-8$ & I2 & I GRAPH & $\begin{array}{l}0 \text { - No graphical output. } \\
1 \text { - One graph is plotted for each fit. }\end{array}$ \\
\hline $9-10$ & I2 & (NWINDO) & $\begin{array}{l}\text { Smoothing window } w \text { in equation ( } 5 \text { ). Default, } \\
0.6 \times \text { FWHM for a peak midway between channels } \\
\text { NFIRST and NLAST }\end{array}$ \\
\hline $\begin{array}{l}11-15 \\
16-20\end{array}$ & $\begin{array}{l}\text { I5 } \\
\text { I5 }\end{array}$ & $\begin{array}{r}(\text { NFIRST) } \\
(\text { NLAST })\end{array}$ & $\begin{array}{l}\text { First and last channel numbers of region to } \\
\text { be searched for peaks. Default for NFIRST } \\
\text { is } 0 \text {. Default for NLAST is last channel of } \\
\text { MCA spectrum. }\end{array}$ \\
\hline $21-25$ & $\mathrm{~F} 5.0$ & (FITCTF) & $\begin{array}{l}\text { If IFIT=1, fitting will be attempted for } \\
\text { peaks with intensity greater than FITCTF. } \\
\text { Default, } 2.0 \text {. }\end{array}$ \\
\hline $26-30$ & F5.0 & (FWCTF) & $\begin{array}{l}\text { When fitting, FWHM will be treated as a } \\
\text { variable parameter for peaks with intensity } \\
\text { greater than FWCTF. Default, } 5.0 \text {. }\end{array}$ \\
\hline $31-35$ & F5.0 & (TAUCTF) & $\begin{array}{l}\text { When fitting, } T \text { will be treated as a varlable } \\
\text { parameter for peaks with intensity greater than } \\
\text { TAUCTF. Default, } 10.0 \text {. }\end{array}$ \\
\hline $36-40$ & F5. 0 & (PKLMT) & $\begin{array}{l}\text { Peak limit parameter } C \text { in equation }(7) \text {. } \\
\text { Establishes smallest fluctuation recognizable } \\
\text { as a peak. Defaull, } 2.0 \text {. }\end{array}$ \\
\hline
\end{tabular}


Table II (continued)

\begin{tabular}{|c|c|c|c|}
\hline Column & Format & Name & Interpretation \\
\hline $\begin{array}{l}41-45 \\
46-50\end{array}$ & $\begin{array}{l}F 5.0 \\
F 5.0\end{array}$ & $\begin{array}{l}\text { (FITBEL) } \\
(F \mid T A B V)\end{array}$ & $\begin{array}{l}\text { Fitting region extends from FITBEL } * \text { FWHM } \\
\text { channels below centroid of first peak to } \\
\text { FITABV * FWHM channels above centroid of } \\
\text { last peak in multiplet. Defaults, } 3.0 \text { and } \\
2.5 \text {, respectively. }\end{array}$ \\
\hline $51-55$ & $\mathrm{~F} 5.0$ & (SEP) & $\begin{array}{l}\text { Peaks will be fitted together as (part } \\
\text { of) a multiplet if the separation between } \\
\text { their centroids is less than SEP * FWHM. } \\
\text { Default, } 4.0 \text {. }\end{array}$ \\
\hline $56-60$ & F5.0 & (XSF) & $\begin{array}{l}\text { Number of channels per inch on plots. } \\
\text { Default, } 10.0 \text {. Note } F \text { format! }\end{array}$ \\
\hline
\end{tabular}


Table III. Format of data control card D.

\begin{tabular}{|c|c|c|c|}
\hline Column & Format & Name & Interpretation \\
\hline $\begin{array}{r}1-10 \\
11-20\end{array}$ & $\begin{array}{l}\text { F10.0 } \\
\text { F10.0 }\end{array}$ & $\begin{array}{l}\text { EO } \\
\text { ECH }\end{array}$ & $\begin{array}{l}\text { Energy calibration is given by } \quad E(\mathrm{keV})= \\
\mathrm{EO}(\mathrm{keV})+E C H \text { (keV/channel) } * \text { (channel number) }\end{array}$ \\
\hline $\begin{array}{l}21-25 \\
26-30\end{array}$ & $\begin{array}{l}\mathrm{F} 5.3 \\
\mathrm{~F} 5.3\end{array}$ & $\begin{array}{l}\text { FWHMO } \\
\text { (FWMEV) }\end{array}$ & $\begin{array}{l}\text { FWHM is given by FWHM (channels) }= \\
\text { FWHMO (channels) }+ \text { FWMEV (channels/MeV) } * \mathrm{E}(\mathrm{MeV})\end{array}$ \\
\hline $\begin{array}{l}31-35 \\
36-40\end{array}$ & $\begin{array}{l}\text { F5.3 } \\
\text { F5.3 }\end{array}$ & $\begin{array}{l}\text { (TAUO) } \\
\text { (TAUMEV) }\end{array}$ & $\begin{array}{l}T \text { is given by } \tau \text { (channels) }= \\
\text { TAUO (channels) + TAUMEV (channels/MeV) } * \text { E (MeV) } \\
\text { Defaults: TAUO, } 0.5 \times(\text { FWHMO + FWMEV); TAUMEV, } 0 .\end{array}$ \\
\hline $\begin{array}{l}41-45 \\
46-50 \\
51-55 \\
56-60 \\
61-65 \\
66-70\end{array}$ & $6 F 5.3$ & $\begin{array}{l}\text { (TAILI) } \\
\text { (TAILS) } \\
\text { (SKULOI) } \\
\text { (SKULOS) } \\
\text { (SKUHII) } \\
\text { (SKUHIS) }\end{array}$ & $\begin{array}{l}\text { Intercept and slope of straight lines giving } \\
\text { tail, lower skewness, and upper skewness as } \\
\text { functions of energy. These parameters are not } \\
\text { variable parameters in PEAKFIND as they are in } \\
\text { SKEWGAUS, but they may be assigned fixed values. }\end{array}$ \\
\hline $71-75$ & F5.3 & (EFFS) & $\begin{array}{l}\text { Slope of straight line giving } \log _{10} \text { (detector } \\
\text { efficiency) versus } \log _{10} \text { (peak energy). } \\
\text { Default, } 1.0 \text {. }\end{array}$ \\
\hline $76-80$ & F5.3 & (EFMAX) & $\begin{array}{l}\text { Energy (in MeV) of maximum efficiency of } \\
\text { detector. Default, } 0.1 \text {. }\end{array}$ \\
\hline
\end{tabular}




\section{ACKNOWLEDGMENTS}

PEAKFIND began as a revision of program PALMUD II, written by Taff and Champion ${ }^{5}$ as a revision of the original program of Mariscotti. 6 It gradually became clear that some rather drastic changes were desirable, and so the program was rewritten almost from scratch, with only a few vestiges of the original programs remaining. Many aspects of SKEWGAUS were incorporated into PEAKFIND, and various additional features have been added in the five years that the program has been in use. Many of the past and present members of the TRISTAN group have contributed helpful suggestions during this time. The peak fitting function, which is also used in SKEWGAUS, was devised by Fred Wohn. The matrix inversion subroutine DUMNV was supplied by the 1.S.U. Computation Center staff. 


\section{REFERENCES}

1. M. A. Mariscotti, Nucl. Instrum. Methods 50, 309 (1967).

2. W. C. Schick,'Jr., USAEC Report No. IS-3460 (1974).

3. W. C. Schick, Jr. and W. L. Talbert, Jr., Phys. Rev. C 9, 2328 (1974).

4. D. G. Scranton and E. G. Manchester, USAEC Report No. IS-2305 (revised 1972).

5. L. M. Taff and P. M. Champion, USAEC Report No. IS-1986 (1968).

6. M. A. Mariscotti, USAEC Report No. BNL-10904 (1966). 
APPENDIX A. PROGRAM DESCRIPTION

PEAKFIND consists of a MAIN program; eight subroutines named INPUT, PKFIND, OUTI, PKFIT, NLLS, FUNCT, DUMNV, and OUT2; and seven labeled COMMON areas named COMI, COM2, COM3, COM4, COM6, COM7, and COM8. Additional subprograms required are all in the standard FORTRAN library, except for the subroutines GRAPH and ORIGIN, which are part of the SIMPLOTTER package and are used only for producing the graphical output.

MAIN establishes the standard values for various parameters; reads cards B, C, and D; assigns default values; and calls the various subprograms. INPUT reads card A and the MCA data. MAIN calls INPUT once for each spectrum to be analyzed.

PKFIND finds the peaks and estimates their centroids, areas, and intensities. MAIN calls PKFIND once for each spectrum to be analyzed. OUT l writes the preliminary output. It groups the peaks into multiplets, determines the channels to be included in each multiplet fit, and finds the initial estimates of FWHM and $\tau$ for each peak. MAIN calls OUTI once for each spectrum to be analyzed.

PKFIT decides whether to perform each fit. It initializes the various arrays that are needed for fiting. After a fit has been performed, PKFIT saves the results for the summary output. MAIN calls PKFIT once for each spectrum to be analyzed.

NLLS does the nonlinear least-squares fitting. It also prints the intermediate output, if required (i.e., the values of the variable parameters after each iteration). This subroutine is very similar to a subroutine of the same name in SKEWGAUS. PKFIT calls NLLS once for each fit to be performed. 
FUNCT evaluates the fitting function and its partial derivatives with respect to the variable parameters. NLLS calls FUNCT once for each channel in each iteration of each fit. This subprogram is a somewhat simplified version of the subroutine of the same name in SKEWGAUS, because of the smaller number of variable parameters (four per peak instead of seven). FUNCT is also called by OUT 2 when the summary output is provided. DUMNV is a standard double-precision matrix-inversion routine.

NLLS calls DUMNV once for each iteration of each fit.

OUT2 provides the summary output and the graphs. MAIN calls OUT2 once for each spectrum to be analyzed.

At the end of analysis of a given spectrum the program cycles back to the beginning to read the first data card for the next spectrum. Any number of spectra may be analyzed in a single execution of the program. An overall flow chart for PEAKFIND is given in Fig. 10. A flow chart for subroutine PKFIND is given in Fig. 11. 


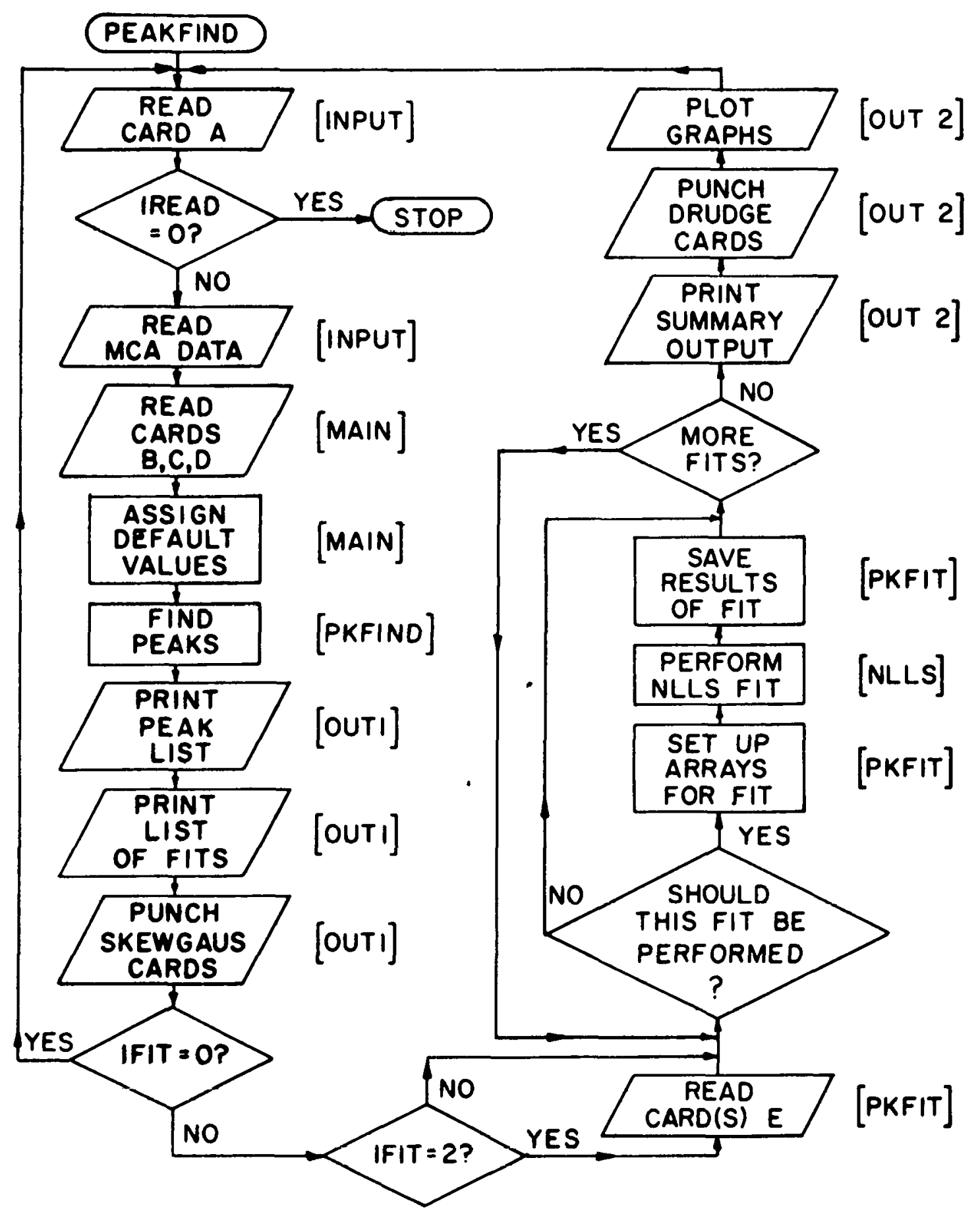

Fig. 10. Overall flow chart for PEAKFIND. The subprograms in which the various operations are performed are indicated in brackets on the right. 

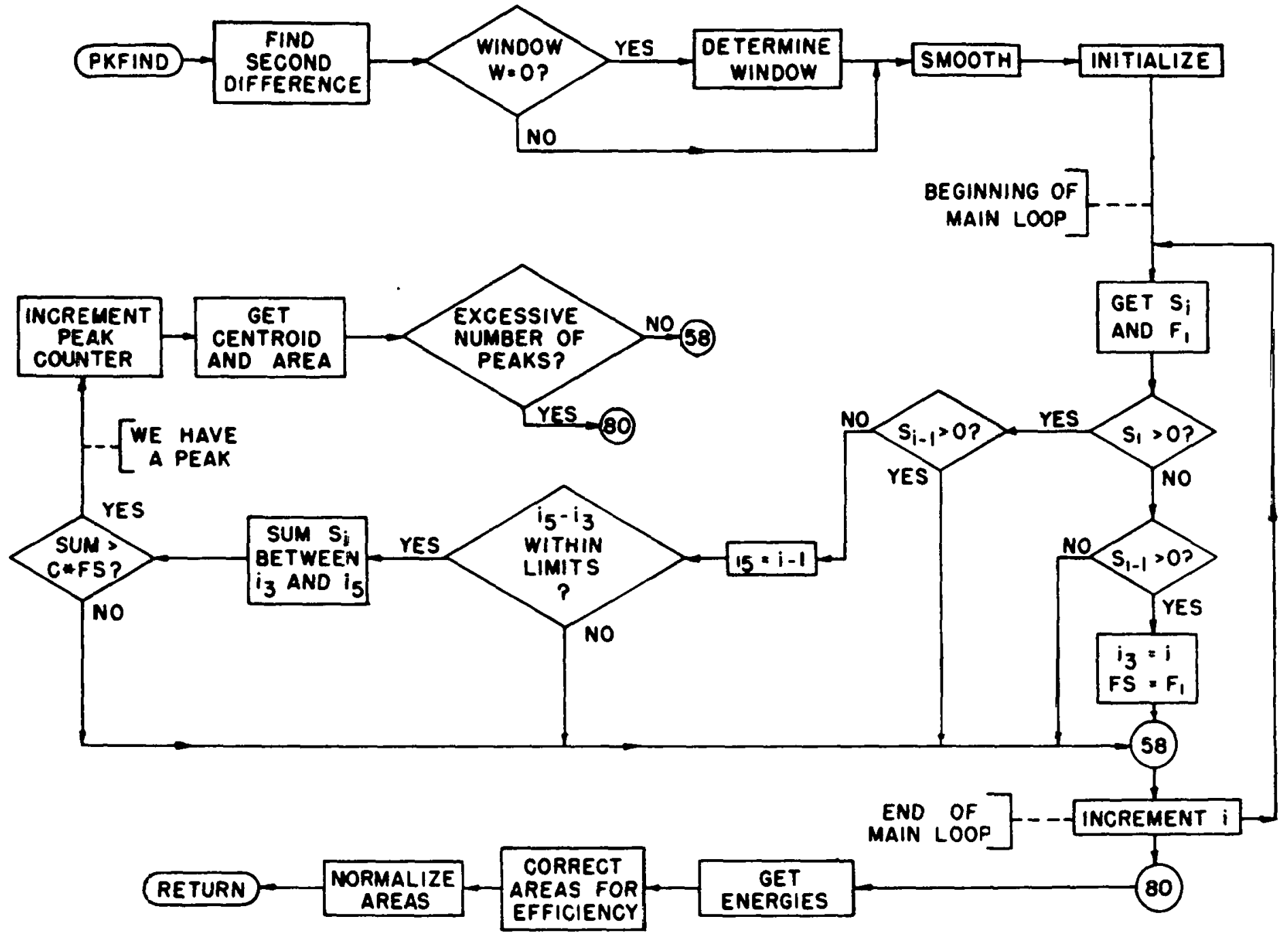

Fig. 11. Flow chart for subroutine PKFIND. 
APPENDIX B. PROGRAM REQUIREMENTS AND LIMITATIONS

The maximum number of channels that may be included in an MCA spectrum is 8192 . This ṇumber may be changed simply by changing the dimension of array DATA in common area COMI, and of array $A$ in subroutine PKFIND. The value assigned to variable LENGTH at the beginning of MAIN should also be changed accordingly.

The maximum number of peaks that can be handled is 250 . This number may be changed by changing the dimension of all arrays dimensioned to 250 in common areas COM2 and COM8. The value assigned to variable MAXPKS at the beginning of MAIN should be changed accordingly.

The maximum number of channels in a given fit is 200 . This number may be changed by changing the dimension of all arrays dimensioned to 200 in COM6, and the dimension of array YCAL in OUT2. In addition, the dimension of array XC in OUT2 should be one greater than the maximum number of channels, and the dimension of arrays $X$ and $Y$ should be 10 greater (to allow for the plotting of five additional channels on each side of the fitting region). The value assigned to variable MXFTSZ at the beginning of MAIN should be changed accordingly.

The maximum number of peaks in a multiplet fit is 9 . To change this number one must change the dimension of all arrays dimensioned to 9 in common area COM7 (and of array TERM, which must be one greater) and also of all arrays dimensioned to 38 . This number is the maximum number of variable parameters, equal to four times the maximum number of peaks plus two. The dimension of arrays in NLLS dimensioned to 38 must similarly be changed. Array $A$ (the coefficient matrix) must have a first dimension equal to twice the number of variable parameters, and array $A A$ (equivalenced to A) must 
be dimensioned to the square of the number of variable parameters. The third argument in the CALL DUMNV statement (card NLLS0770) must also be equal to the maximum number of variable parameters. The value assigned to MLTPLT at the beginning of MAIN is the maximum number of peaks per fit. The maximum number of iterations permitted per fit is 30 . This number may be changed by changing the value assigned to MAXIT at the beginning of MAIN. The assignment of most other standard and default values is also done in MAIN so that they may easily be changed if desired. As we observed in the Introduction, the load module for PEAKFIND is about 156 kilobytes long when no overlays are used. An overlay tree that will permit execution in a 128 kilobyte region of core is generated by the following set of instructions to the linkage editor:

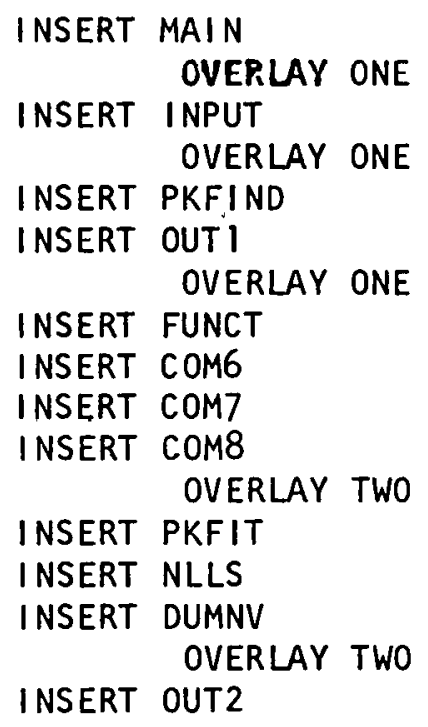


CCMMCN / COMI / LENGTH.NFIRST. NL AST, NWINDJ . DATAR 8192)

MAI NOOSO

CCMMON /COM2, MAXPKS.NFEAKS.POS (250). ENERGY (250). AREA(250).

MAINOO4O

MAI NOOSO

MAINOO60

1 FWHM(250), T AU (250), NPKS( 250), FITLO(250), FI THI (250), NFITS

CCNMCA /COMJ/ EO .ECH,FWHMO .FWMEV.TAUO .TAUMEV.SKULOI, SKU_OS.

MAINOOTO

MA INOOBO

MAI INOO9O

MAI NOIOO

1 EPSO,EFFS, EFMXL G. EFTERM. PKLMT, NRDR. NPRTR . NPNCH

COMMCN /COMA/IFIT.IPR INT.IPUNCH.IGRAPH, IFIX, MLTPLT, MXFTSZ,EPSHT,

1 EPS XO.EPSFW.EPSTAU, EP SA, EPSB,DIFLIN,CONST, SEP, FI TABV,FI TBEL.

C

I ITCTF .FWCTF. TAUCTF .XSF

DI MENSICN LABEL(20)

$\mathbf{c}$

$$
\text { NFDR }=5
$$

$c$

NPRTR $=6$

NPNCH $=7$

$c$

$c$

LENG TH=8192

MAXPKS $=250$

c

5

$=$

$c$

$-$

IC CALL INPUT (DATA,LENGTH,I2)
FILE NUMBER FOR CARD READER

FILE NUMBER FOR LINE PR INTER

FILE NUMBER FOR CARD PUNCH

MAXIMUM NO. OF CHANNELS IN MCA SPECTRUM

MAXIMUM NG. OF PEAKS THAT MAY BE HANDLED

MAXIMUM NC. OF CHANNELS IN ANY ONE FIT

MAX IMUM NC. OF PEAKS IN ANY ONE FIT

MAXIMUM NO. OF ITERATIONS PERMITTED PER FIT

MA INOIIO

MAINOI20

MA INOI 30

MAINOI40

MAINOI 50

MAINO 160

MAI NOI 70

MAINOI 20

MAINOI90

MAINO200

MAINOZIC

MA I NOZ2 20

MA.INO230

MAINO240

MA INO250

MAINO 260

MAI N0270

MAINO280

MAI N0290

MA INO300

MAINO 310

MAINO320

MAINO330

MA INO340 


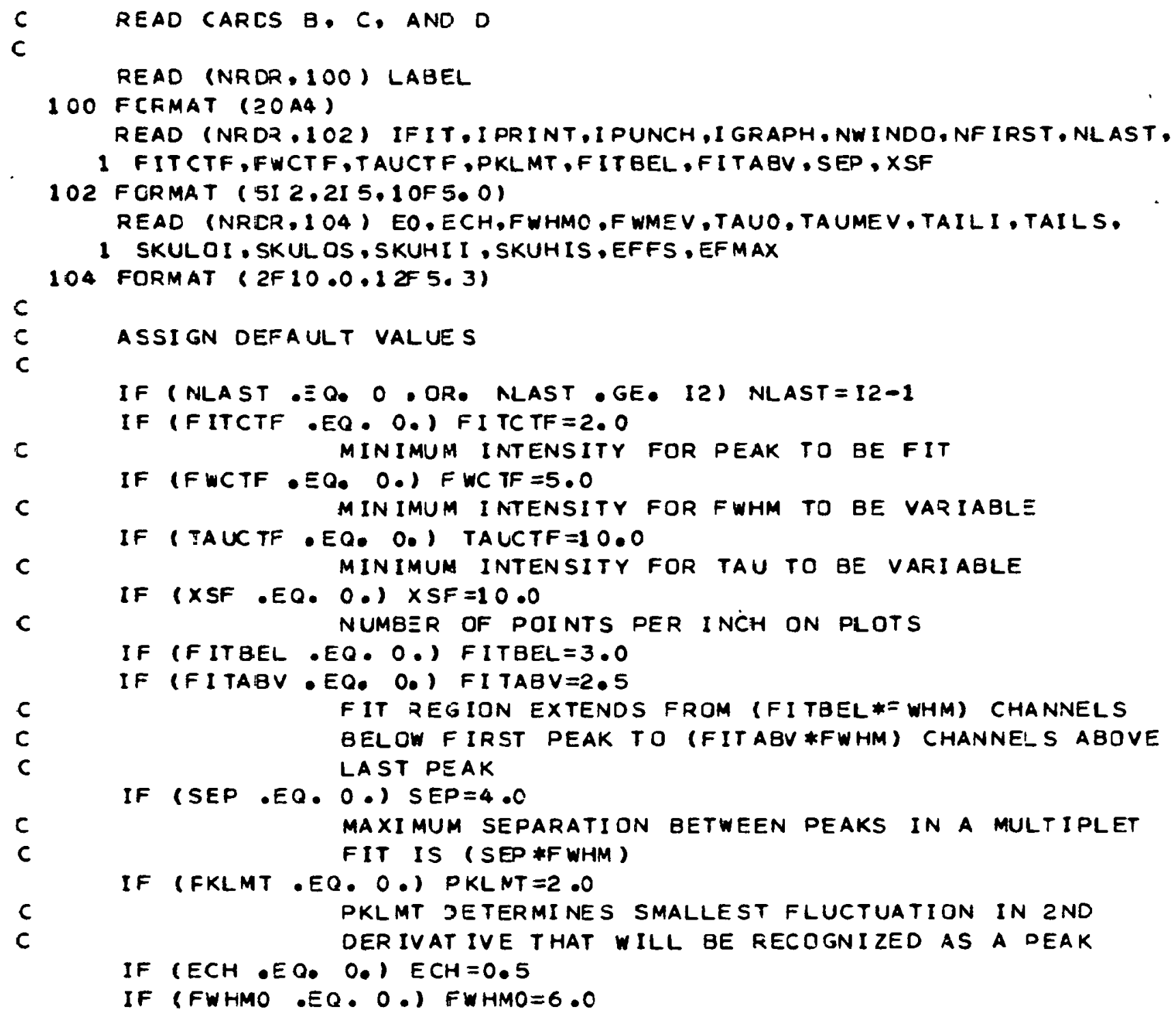

MA I NOSOO

MA INO5IO

MAINO520

MAINOS30

MAINOS40

MA INO550

MA INOS60

MA INOS70

MAI INO580

MAINOSOO

MAINO600

MA INOEIO

MAIIN0620

MA I N0630

MA INO640

MAI IN0650

MAINO660

MA I NO 670

MAIN0680

MAINO690

MA I NO700 
IF (TAUO .EO. O.) TAUO $=(F W H M O+F W M E V) / 2.0$

MAINO 710

IF (EFFS .EQ. O.) EFFS $=-1 \cdot 0$

$E F F S=-A B S(E=F S)$

c

$c$

C

$c$

$c$

$c$

A SKULO=2

ALCI $=$ ASKULO-

NSKUHI $=5$

NHI $1=$ N SKLHI -1
MAINO720

MA IN 0730

MAI NO 740

MA INO750

MAI NO 760

MAINO770

MAINOT80

MAINO790

MA INO800

MAINOBIO

MAINOB20

MA INOB 30

MAI IOB4O

MAINO850

MAINO860

MA INOE70

MAINO880

MAI NOB9O

MAINO900

MAINO910

MA INO920

MAINO930

MA I NO940

MAINO950

MAINO960

MAINOS7O

MAINO980

MAINO990

MAIN 1000

MAINIOIO

MAINIO20

MAINIO 30

MAIN 1040

MAINIO50 


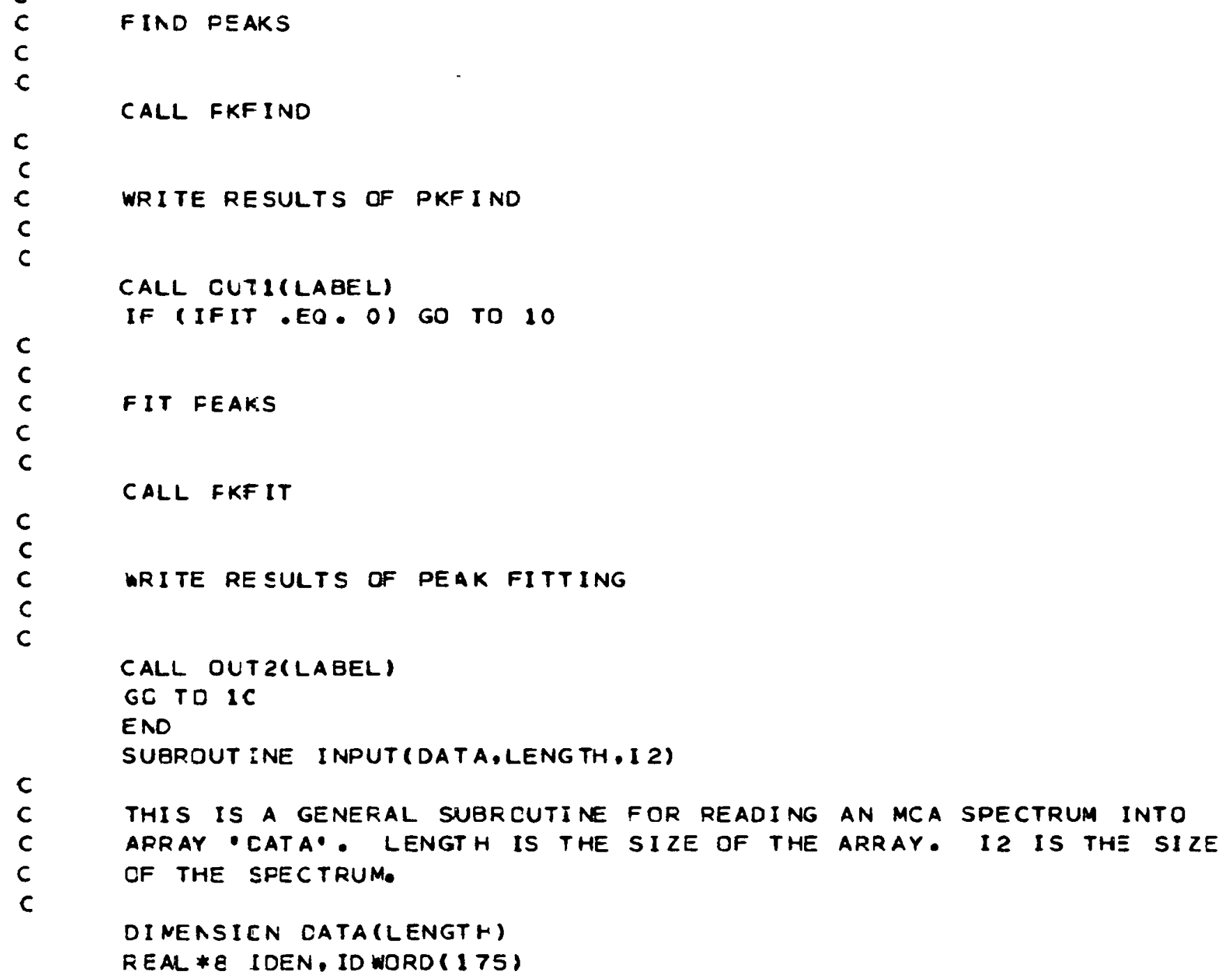

MAIN 1060 MAIN 1070

MAINL 080

MAIN 1090

MAIN1100

MAINIIIO

MAINII20

MAINII30

MAINII40

MAINIISO

MAINII 160

MAIN 1170

MAIN1 180

MAINII90

MAINI 200

MAINI210

MAIN 1220

MAIN1 230

MA IN 1240

MAIN1250

MAIN1 260

MA IN 1270

MA INI 280

MAINI 290

MAIN1300

MA INI 310

MA IN 1320

INFUOOIO

INPU0020

INPUOO 30

INPUO040

INPU0050

INFUOOSO

INPUO070

INPUOO 80 


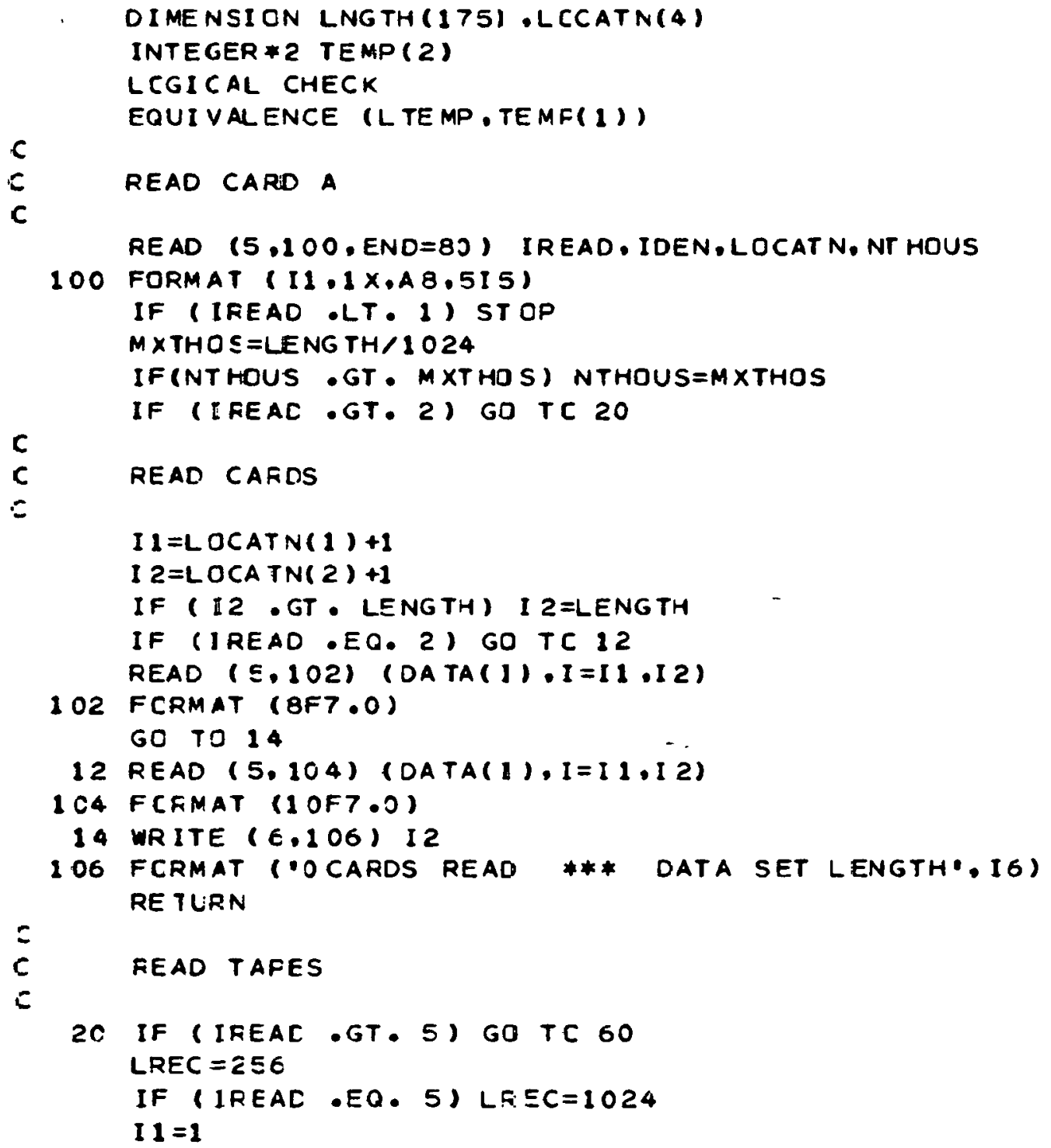

INPUO090

INPUO100

INPUO110

INPUO 120

I NPUO 130

INPUO140

INFU0150

INPUO160"

INFUO 170

INFUO180

INPU 0190

INPUO200

INPUO28 0

I NPUO 220

I NPUO230

INPUO240

INFU0250

INPUO 260

INPUO270

INPUO280

INPUO 290

INPUO 300

INPUO 310

INPUO320

INPLO 030

INPUO 340

INPUO350

INPUO 360 INPUO370

INPUO380 INPUO 390

INFU 0400 INPUO 410

INPU0420 INPUO 430 


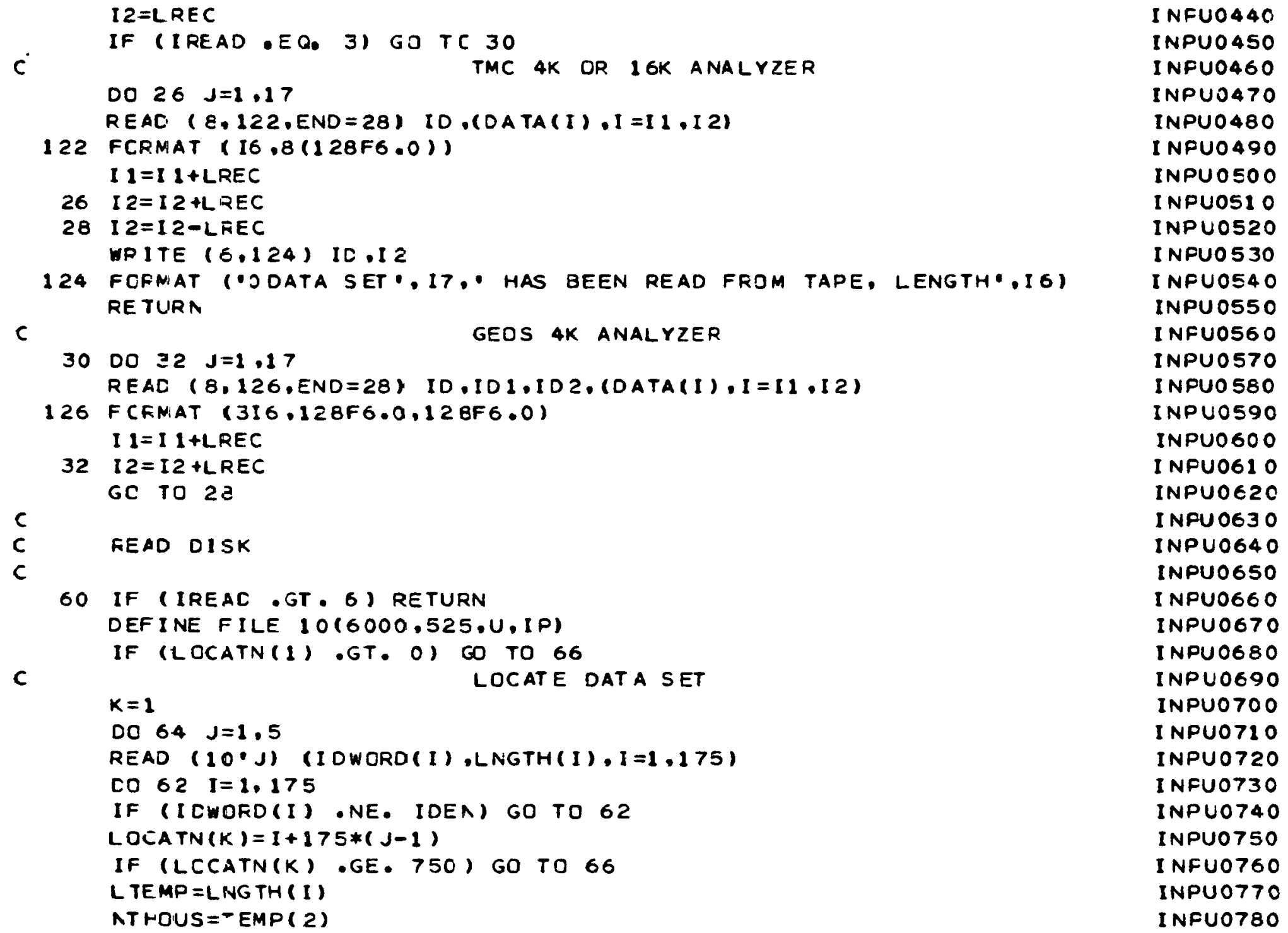

I NFUO440

INPUO 450

INPU0460

INPUO470

INPUO 480

I NFUO490

INPUOSOO

INPUOS10

INPUO520

I NPUO 530

I NFU 0540

INPU 0550

I NFU0560

INPUO570

INPUO 580

INPUO590

INPU0600

I NPU0610

INPUOE2O

I NFU 0630

INPUO640

INPU0650

I NPUO660

INPUO670

I NPU 0680

INPU0690

INPU0700

I NPUO710

INPUO720

I NFU0730

INPU0740

INPUO750

I NFU0760

INPUO770

INFU0780 
NTHI S=TEMP $(1) * 4$

IF (NTHIS .GE. NTHOUS) GO TO 66

INPUO790

$K=K+1$

62 CONT INUE

64 CCNTINUE

WR ITE (6.130) IDEN

I NPUO800

INPUOB10

INFU0820

INPU0830

INPUO 840

130 FCRMATI:- *** ALL OF DATA SET NO. . A8. COULD NOT BE FOUND IN TAINFUOBSO IBLE OF CONTENTS')

IF (LOCATN(I) LLE.O) STOP

$\wedge$ THCL $S=(K-1) * 4$

66 JSTCP $=2 * N T$ HOUS

READ DATA SET

INPUOB60

INFU0870

INPU0880

I NFUO890

I NPU0900

$J j=1$

$11=1$

$12=512$

CO $74 K=1.4$

IFCINT $=8$ \#LOC AT $N(K)+1$

IF (IFOINT. LE. 8) GO TO 76

CC $72 \mathrm{~J}=1.8$

READ (10, IPOINT) IDWORD(J), (DATA (I),I=11, I2)

IF ( IOWORD(J) .EQ. IDEN) GO TO 67

WRITE $(6,132)$ IDEN, IDWCRD (J), JJ

132 FORMAT $1 \cdot$ * ** POSSIBLE ERROR - YOU ASKEO FOR DATA SET $\because A 8$,

- BUT IDENT IF ICATION WORD $\because A 8$. APPEARS at THE BEgINNING OF *

\& $\operatorname{RECCRD} \cdot, 13)$

67 IF (JJ GE. JSTOP) GO TO 76 $J J=J J+1$

IF ( 12 . GE . LENG TH) GO TO 76

$I 1=I 1+512$

$I \Sigma=12+51 \hat{2}$

IFCINT = IFO INT +I

72 CCATINUE

74 CONTINUE

76 WRITE $(6,134)$ IDEN, LOCATN

134 FORMAT ("ODATA SET ".AE," HAS BEEN READ FROM LOCATIONS. .414 )

INPUO910

INFU0920

INPU0930

INFU0940

I NPUOS50

INPU0960

I NFU0970

INPUO980

INPU0990

INPU1 000

INPU1010

I NPU1020

INPU 1030

I NFUI 040

INPU1 050

INPU 1060

I NFU1 070

INPU 1080

INPUI 090

INPU1100

INFU 1110

INFU1120

INPU 1130 
RETUFA

INPUII40

80 STOP

END

SLBRDLTINE PKFIND

FEAK FINDING PROCEDURE REFERENCE: M.A. MARISCOTTI. NUC_. INST. AND METH.. VOL. 50 (1967). PAGES 309-320

COMMON /COMI/ LENGTH, NFIRST, NLAST, NWINDO,DATA(8192) CCMMON / COM2/ MAXPKS.NPEAKS.POS( 250). ENERGY(250).AREA( 250$)$.

1 FWHN(250) . TAU (250). NPKS (250) .FITLO(250), FITHI (250). NFITS COMMON ICJM3, EO.ECH,FWHMO .FWMEV, TAUO. TAUMEV. SKULOI, SKULOS.

1 SKUHII, SKUHIS, TAILI, TAILS, NSKU, O, NS CUHI, NLO 1, NHII, MAXIT, ITO.

1 EPSD,EFFS, EFM XLG. EF TERM,PKLMT, NRDR, NPRTP.,NPNCH

DIMENSION A(8192),XN(15)

FEAL FCTR(15)/6.. 23., 82..184..350.+506..939..1392..1974..

$12700 \ldots 3586 \ldots 4648, .5902$. . $7364 . .9050 . /$.NOPEAK

I $M I N=N F$ I RST +1

I MAX $=$ NL AST +1

$I I=I N I N+1$

$I 2=I M A X-1$

DO $20 \quad I=I 1, I 2$

2C. $A(I)=D A T A(I+1)-2 \cdot C * D A T A(I)+D A T A(I-1)$

$A(I M I N)=0$.

$A(I M A X)=0$.

FIND NWINOO

CHMID $=$ (NFIRST $+N_{-}$AST $/ / 2$

EMID $=(E O+E C H * C H M I D) / 1000$.

FWM ID $=F W H M O+F W M E V * E M I D$

IF (NWINDO .EQ. O) NWINDO $=0.6 * F W M I D+0.5$

INPU 1145

I NFUI 150

PKFDO010

PKFD0020

PKFD 0030

PKFDO040

PKFDOO50

PKFD0060

PKFDO070

PKFD 0080

PKFDO090

PKFO0100

PKFDOI 10

PKFDO120

PKFD0130

PKFDO140

PKFD 0150

PKFCO 160

PKFO0170

PKFD 0180

PKF00190

PKFO 0200

PKFOO210

PKFD0220

PKFDO230

DKFD0240

PKFD 0250

PKFDO 260

PKFD0270

PKFDO280

PKFD0290

PKFD 0300

PKFDO 310

PKFDO320 
IF (NWINDO LLE. 15) GO TO 21

PKFDO 330

WRITE (NPRTR,IOO) NWINCO

PKFD 0340

100 FORMAT (* *** ERFOR--NWINOO IS'.I3.' WHICH IS GREATER THAN I5!IPKFDO35O STCP

$21 N 1=N W I N D C-1$

$\checkmark$ INDOW=NWINDO

IF (RI LE. O) GO TO 32

$0022 I=1 \cdot N I$

$22 \times N(I:=N W I N D O-I$

SMOOTH SECOVD DIFFEFENCE 4 TIMES WITH AN NWINSO ITANNEL WINDOW

$I I=I H I N+N I$

$I 2=I$ MAX $-N I$

DO $30 \quad 11=1.2$

DC $26 I=I 1, I 2$

SLM $=I N D C W * A(I)$

DO $24 L=1$.N 1

$24 S U M=S U M+X N(L) *(A(I-L)+A(I+L))$

$26 A(I-N 2)=S U M$

DO $28 \quad 1=11 \cdot 12$

$13=11+12-1$

$28 A(I-3 ;=A(I 3-N I)$

$\Xi$

DO $30 L=1 \cdot N 1$

$A(I M I N-1+L)=A(I 1)$

$A(I M A X+1-L)=A(I 2)$

$c$

30 CONT INUE

TAKE CARE OF ENDS

PKFD0360

DKFDO 370

PKFDO380

PKFO 0390

PKFDO400

PKFD 0410

PKFO0420

PKFDO430

PKFDO440

PKFDO 450

PKFDO460

PKFDO470

DKFDO480

PKFD 0490

PKFDO5OC

PKFDOS10

PKFD0520

PKFD0530

PKFD 0540

PKFDO550

PKFD $\cong 560$

PKFDO570

DKFD0580

PKFD 0590

PKF00600

PKFDOEIO

PKFD0620

PKFD0630

DKFD 0640

PKFDOE50

PKFD 0660

PKFDOE 70

FACTOR=FCTR (NWINDO) 
$F I=S O R T(A B S(F A C T O R * D A T A(I M I N))) / 1000$

IF ( DATACI) .LT. 1.) FI=SORT(FACTOF) $/ 1000$.

PKFD 0680

PKFDOG90

PKFDO700

PKFDO710

PKFD0720

DKFD 0730

PKFDO740

PKFO 0750

PKFD0760

PKFDO770

DKFD 0780

PKFOO790

PKFDO800

PKFO 0810

PKFDOB2O

PKFDO830

PKFD0840

PKFDOE50

PKFDO860

PKFDOB7O

PKFD 0880

PKFD0890

PKFO 0900

PKFD0910

PKFD092C

DKFO 9930

PKFDO940

PKFD0950

PKFD0960

PKFD0970

PKFD 0980

PKFD0990

PKFDI 000

DD $44 K=I 3.15$

PKFD 1010

SUM $=-S U M / 1000$.

PKFO1020 


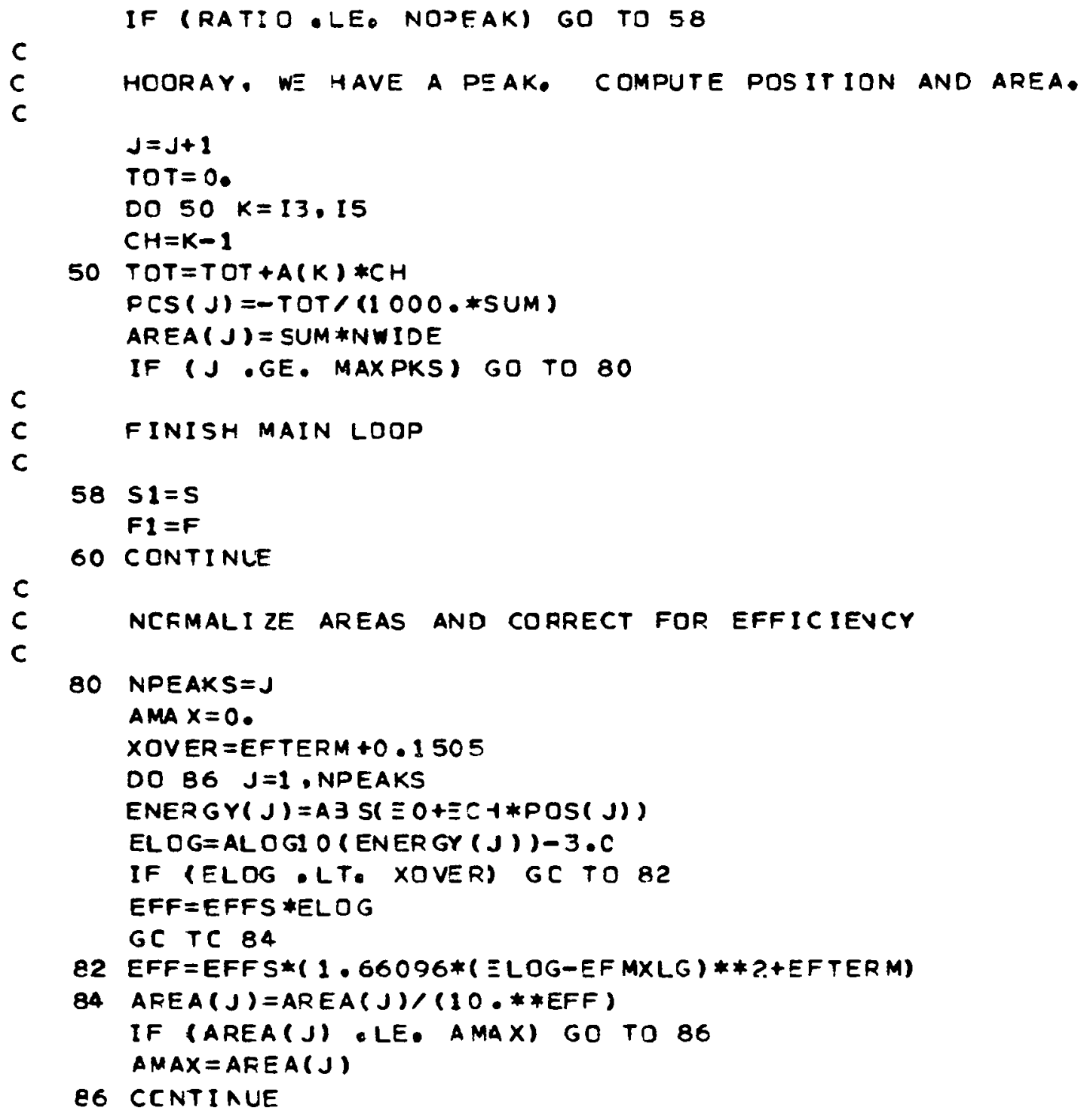

PKFD1030

PKFD1 040

PKFD 1050

PKFD1060

PKFD 1070

PKFD1080

PKFD1 090

PKFD 1100

PKFDI 110

PKFO 1120

PKFD 130

PKFD1 140

PKFD $11 \leq 0$

PKFO1 160

PKFD 1170

PKFD1 180

PKFO1190

PKFO 1200

PKFD1 210

PKFD 1220

PKFD1230

PKFO1240

DKFD 1250

PKFD1 260

DKFD 1270

PKFD1280

PKFO 1290

PKFD 1300

PKFDI 310

DKFD 1320

PKFDI 330

PKFDI34C

PKFD 1350

PKFO1 360

DKFD 1370 
CO $88 \mathrm{~J}=1$. NPEAKS

PKFD1 380

88 AREA $(J)=100$ * *AREA(J) /AMAX

PKFD 1390

RETURN

END

SUBROUTINE OUTI(LABEL)

COMMON /COMI / LENGTH, NFI RST, NLAST, NW I NDO, OAT A (B 172$)$

CCMMCN /CJM2/ MAXPKS, NPEAKS, DOS( 250), ENERGY(250). AREA( 250$)$,

1 FWHM(250), TAU (250), NPKS (25) ), FITLO(250), FITHI (250), NFITS

COMMON /COM $3 /$ EO.ECH, F WHMO .F WMEV.TAUO . TAUMEV , SKULOI, SKULOS,

PKFD1400

DKFD 1410

DUT 10010

OUT10020

OUT 10030

OUT1 0040

OUT1 0050

OUT 10060

SKUHII, SKUHIS, T AILI, T AILS, NSKULO, NSKUHI, VLJ 1, NHI 1, MAXIT I TO,

כUT 10070

1 EPSO,EFFS, EFMXLG,EF TE RM,PKLMT , NRDR, NDRTR, NPNCH

COMMCN /COM4/ IFIT, IPR INT, IPUNCH,IGPAPH,I I I,MLTPLT,MX $=T S Z, E P S H T$,

1 EPS XO.EDS=W, EPSTAU, EPSA,EPSB,DIFLIN, CONST, SEP, FITABV, FITBE_,

OUT1 10080

1 FITCTF, FWCTF, TAUETF, XSF

DINENSI CN LABEL $(20)$

INTEGER FITHI,FI R.O

FRINT OUT RESULTS OF FKF IND

OUT10100

OUT 10110

OUT10120

OUT 10130

OUT10140

OUT10150

WRITE (NPRTR,100) LABEL

100 FORMAT (IHI.25X.20A4/1HO)

WRITE (NPRTR, 102 ) NFIFST, NLAST, NWINJO,PKLMT

102 FCFMAT (' PEAKFIND SEARCH BETWEEN CHANNELS ', 14,' AND 'I I4,

$110 \times$, 'SMOIJTHING WINJOW = , I3,10X, PPEAK LIMIT PARAMETER = , F5 .11

WRITE (NPRTR,104) FITCTF,FITBEL, EO,ECH,TAILI, TAILS

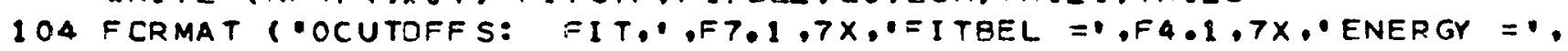

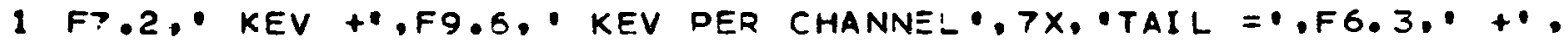

1 FE.3." FER MEVं।

WRITE (NPFTR, 106) FWCTF,FITABV,FWHMO ,FWMEV.SKULOI, SKULOS

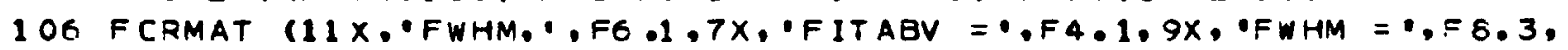

1 ' + '.F7.3.' PER MEVI.19X.'SKULO = .,F6.3.' + .,F6.3..' PER MEV'1

WRITE (NPRTR, 108 ) TAUCTF,SEP, TAUC, TAUMEV, SKUHI I, SKUHIS

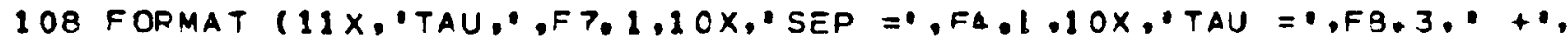

1 F7.3, P PER MEV $., 20 X, \cdot$ SKUHI $=,, F 6.3,0^{\circ}+, .=6.3,0^{\prime}$ PER MEV $/ 2 H-1$

OUT 10160

OUT10170

OUT 10180

OUTI0190

OUT10200

OUT 10210

OUT1 0220

OUT10230

OUT1 0240

OUT 10250

OUT10260

OUT10270

OUT 10280

OUT1 10290

DUT 10300

OUT1 0310 
WRITE (NPRTZ.110)

DEAK NUMBER CHANNE:-

EYEZGY०, 9X

DUT 10320

1 - INTENSITY TOBE FIT//1HOI

OUT10330

OUT 10340

OUT1 0350

IF (AREA(J) .GT. FITCTF) GO TO 10

WRITE (NPRTR.112) J.POSI J) .ENERGY (J).AREA(J)

112 FCRMAT (12X.13,10X,F7.2,10X,F7.2.10X,F 7.3) GO TO 12

10 WRITE (NPRTR I14) J.POS(J),ENERGY(J),AREA(J)

114 FOFMAT (12X.13,10X,F7.2,10X,F7.2.10X,F7.3,8X,1H*)

12 CONTINUE

IF (NPEAKS ILT • MAXPKS) GO TO 14

WRI TE (NPRTR .116) MAXPKS

C

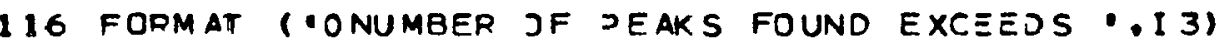

C WRITE OUT PARAMETERS FOR FITS

14 WFITE (NPRTR .120)

120 FORMAT 1

SUMMARY OF PARAMETERS FOR FITS"

OUT10360

OUT 10370

OUT1 0380

OUT 10390

OUT1 04C0

OUT10410

OUT 10420

OUT 10430

OUT 10440

OUT10450

OUT10460

OUT 10470

DUTI 0480

OUT 10490

INERG FIRST LAST FWHM TAU CENTZOIDS.1.NO.1.17X.

1 'CHAN EHAN'/1

CO $16 \mathrm{~J}=1$. NP EAKS

FWHM( $J)=F W H M O+F W M E V * E N E R G Y(J) / 1000$.

16 TAU( $J)=$ TAUO+TAUMEV *ENERG $Y(J) / 1000$.

C MAIN LDOP-J LABELS PEAKS. K COUNTS FITS

$c$

DETERHINE NUMBER OF PEAKS IN EACH FIT. ALSO IST AVD - AST CHANYELS

$J=1$

$K=1$

$20 \quad J 1=J+M L T P_{-} T-1$

FITLD(K)=POS $(J)-F I T B E L$ *FWHM(J)

IF (FITLO(K) \&LT. NFIRST) FITLC(K) =NFIRST

DO $22 \mathrm{JJ}=\mathrm{J}, \mathrm{JI}$

EOUT 10500

DUT10510

DUT 10520

OUT1 0530

OUT1054C

DUT 10550

OUT1 0560

OUT10570

OUT1 058C

OUT10590

OUT $10 \in 00$

DUTIOEIO

OUT 10620

DUT1 DE 33

OUT10640

OUT 10650

OUT1 10660 
IF ( $J J$ EO. NPEAKS) GO TO 24

IF ( $(F O S(J J+1)-P O S(J J)) \cdot G T \cdot S E P * F W H M(J J))$ GO TO 24

DUT 10670

IF (POS(JJ+L)+FITABV*F HM(JJ+1). GE. FITLO(K)+MXFTSZ) GO TO 24

22 CCNTINUE

$J J=J+M L T P L T-1$

$24 \operatorname{NPKS}(K)=J J-J+1$

FITHI $(K)=P O S(J J)+F I T A B V * F W H M(J J)$

IF (FITHI(K) - GT. NLAST) FITHI (K) =NLAST

IF (FITHI(K)-FITLO(K) . GE. MXFTSZ) FITHI(K)=FITLJ(K)+MXITSZ-I

WRITE (NPRTR,122) K, APKS(K),ENERGY(J),FITLO(K),FITHI(K),FWHM(J).

1 TAU (J), (POS (I),I=J.JJ)

122 FCRMAT (1X.I3.I5.F9.1.217.2F7.2.9F9.2)

C

$c$

PUNCH CAROS IF IPUNCH=1 OR 3

IF ( IPUNCH .EQ. O .DR. IPUVCH.EO. 2 , GO TO 28

WRITE (NPNCH.124) NPKS(K), ENERGY (J),FITLO(K),FITHIIK),K

124 FORMAT (I2.' 1 I ,F6.1.' KEV・.10X.215.37X.13)

CO $26 \quad I=J . J J$

WRITE (NPNCH.126) POS(I)

126 FCRMAT $(111.18 \times, F 10.2)$

26 CCNTINUE

28 IF (JJ.GE. NPEAKS) GO TO 30 $J=J J+1$

$K=K+1$

GC TO 20

C

30 NFI T S $=K$

WRITE (NPRTR.130) NFITS

130 FORMAT (1HO/1HO.20X. NUMBER OF FITS IS . I3) RETURN

\section{END}

C

SURROUTINE $D K=I T$

COMMON /COMI / LENGTH, NFIRST, NLAST, NN INDO, DATA( 8192$)$

OUT1068C

DUT 10690

DUT 10700

OUT 10710

OUT1 0720

OUT10730

OUT 10740

OUT10745

OUT 10750

OUT10760

OUT10770

NT 10780

OUT1 0790

OUT 10800

OUT10810

OUT10820

OUT 10830

OUT10840

OUT 10850

OUT1 0860

DUT10870

OUT 10880

OUT10890

JUT 10900

OUT1 0910

OUT10920

OUT10930

OUT1 0940

OUT 10950

OUT $1096 \mathrm{C}$

OUT 10970

PKFTO010

PKFT0020

PKFTO030 
CCMMCN / COM2, MAXPKS.NFEAKS.POS(250), ENERGY(250). AREA(250).

1 FWHM(250). TAU(2.50), NPKS(250), FI TLO(250), FITHI (250), NFITS

CCMMCN / COM 3/ EO.ECH.FWHMO.FWMEV. TAUO.TAUMEV . SKULOI, SKULOS,

1 SKUHII , SK UHIS, TAILI .TAILS,NSKULO, NSKUHI, NLOI . NHII , MAXIT, ITR,

1 EFSO,EFFS, EFMXLG.EFTEFM, PKLMT, NPDR. NORTR, NPNCH

CCNMCN /COM4/ IFIT,IPR INT, IPUNCH,IGRAPH,IFIX, MLTPLT, MXFTSZ,EPSHT,

1 EPSXO. EPSFW. EPSTAU, EPSA.EPSB,DIFLIN, CONST, SE = ,FI TABV,FI TJEL,

1 FITCTF, FWC TF, TAUCTF, X SF

COMMON /COM6/W(200),X(200), Y(200),NPTS. EDS(38).STDE(38).

1 VAR I I CONV ITRATN.SCAREA

COMMON /CJM7/ P( 38). IHQLD(38), DERIV(38), TERM(I C). ALPHAI (9).

1 ALPHA2 (9), BET A1 (9), BETA2 (9), BETA3(9), TA IL (9), SKULO(9), SKUHI (9).

1 NPRMS,NP, N=REE,NJ,I OPT, XF IRST, BPRIME

COMMCN / COMB/ NFRSV(25C), ICNVSV(250), I TRNSV(250), VARSV(250),

1 HEIGHT(250).SDHT(250),SDXO(25)),SDFW(250).SOTAU(250).ASV(250).

1 ESV(250).LFIT(2.52)

PEAL NEV

INTEGER FI THI , FI TLO

INTEGER $* 2$ NFRSV, ICNVSV,ITRNSV

LOGICAL*I L $=I T$

C

C

READ CARDIS) E

IF (IFIT ONE. 2 ) GO TO 6

READ (NFDR 110 ) (LFIT(L),L=1.NFITS)

10 FORMAT ( $30 \mathrm{~L} 1)$

C

MAIN LOOP--L LABELS FITS, J LABELS PEAKS. K LABELS DAPAMETERS

6 JMA $x=0$

DO $50 \quad L=1$, NFITS

JNI $N=J N A X+1$

$J M A X=J M A X+N P K S(L)$

DECIDE UHETHER TO PERF CRM FIT

PKF TOO4O

PKFTOO5O

DKFTO060

DKFT0O70

PKF T0080

PKFT0090

PKFTOIOC

DKFTO110

PKFTO120

PKF T0130

PKFTO140

DKFTO150

PKFTO15C

PKFTO170

OKFTO180

PKFTO19C

PKF T0200

DKFT 2210

PKF T0220

PKFT0230

PKFT0240

PKF T0250

PKFTO260

PKFT0270

PKFT0280

PKFT0290

PKF T0300

PKFTO310

PKFTO 320

PKFTO 330

PKFT 0340

PKF T0350

PKFTO360

PKFT037C

PKFTO 380 
IF (IFIT.EO. 2) GO TO 10

DO 8 J=JMIN.JMAX

IF (AREA(J) LLT. =ITCTF) GOTO 8

LFIT $(L)=$.TRUE.

GC TC 12

8 CONTINUE

LFIT $(L)=$.FALSE.

GO TD 50

C

10 IF (.NOT. LFIT(L) , sO TO 50

c

$c$

12 I MIN $=F I$ TLO(L)

IMAX $=F I T H I$ IL

NFTS $=$ INAX-IMIN+I

$X(1)=I M I N$

$X F I R S T=X(1)$

$Y(1)=D A T A(I M I N+1)$

IF (Y(1) .LT. 1.0$) Y(1)=0.5$

$Y M A X=Y(1)$

DO $14 \quad I=2, N>T S$

$X(I)=X(I-1)+1$.

$Y(I)=D A T A(I M I N+I)$

IF $(Y(I) \cdot L T \cdot 1.0) Y(I)=0.5$

IF (YII) .LE. YMAX) GOTO 14

YMAX $=Y($ I )

14 CCNTINUE

$c$

$c$

INIT IAL IZE WEIGHT ARRAY

$C 1=1.0-$ CONST

C2 $=$ C CNST *YMAX

$D 2=0$ IFL IN*DIFL IN

CO $16 \quad I=1$, NPTS

PKF T039O

PKFTO 400

PKF T0410

PKFT 0420

PKFTO430

PKF TO44O

PKFTO450

PKF TO460

PKFT0470

PKFT0480

PKF T0490

PKFTO500

PKFTOS10

PKFT0520

PKFT0530

PKF TOS4C

PKFTO550

OKFT0560

PKFT 0570

PKFTOS80

PKFTO590

PKFTO60C

DKFTO610

PKFTO620

PKF T0630

PKFTOG40

PKFTO65O

PKF TOE60

PKFT 0670

PKF T0680

PKFT 0690

PKFT 0700

PKF TOT10

PKFTO720

PKFTO730 
$N J=N P K S(L)$

$\Lambda P=4 * \Lambda J$

NPRM $S=N P+2$

$P(N P+1)=r(1)$

$B P F I M E=(Y(N P T S)-Y(1)) /(X(N P T S)-X(1))$

$D(N P+\geq)=B P R I M E+1000$.

$1 H C L D(N F+2)=1$

(HOL $D(N P+2)=1$

$E F S(N P+1)=E P S A$

C

$E P S(N P+2)=E D S B$

INITIALIZE PEAK PAZAMETERS

PKFT 0780

PKFT 0790

PKFT0800

PKFTD810

PKFT0820

PKFTOP 30

PKFTO84O

PKFT0850

PKFT0860

PKF T08>0

PKFTC89C

PKFT0890

PKFTO90O

PKFT0910

DO $20 J=J M I N$. JMAX

PKFT0920

PKFT0930

PKFT0940

PKFT0950

PKFT0960

PKFT0070

PKFT 0980

PKFT0990

PKF T1000

PKFT 1010

PKFT1020

PKFT 1030

PKFT1040

DKF T 1050

I HOL $C(K+2)=1$

IF ( $\triangle$ REA(J) $\quad L T$. FWCTF) IHOLD $(K+2)=0$

PKFT 1060

$\operatorname{EPS}(K+2)=\equiv P S F W$

$c$

$P(K+\geq)=\operatorname{TAU}(J)$ 


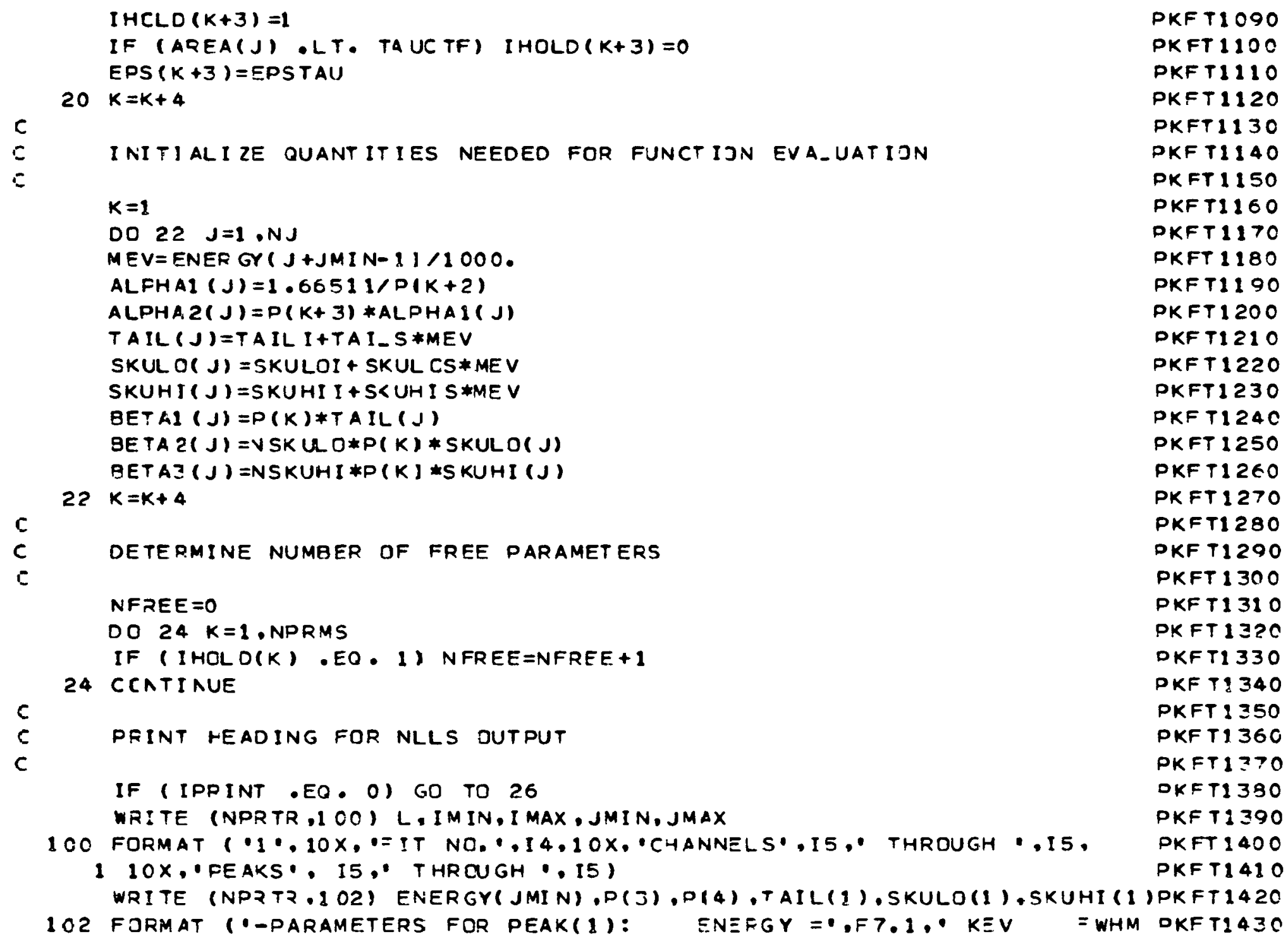

INITIALI ZE QUANTITIES NEEDED FOR FUNCTIJN EVA_UATION

$K=1$

$D O 22 J=1 \cdot N J$

MEV = ENER GY $(J+J M I N-1) / 1000$.

ALFHAI $(J)=1.6651 \mathrm{l} / \mathrm{P}(K+2)$

ALPHA $2(J)=P(K+3)$ *ALPHAI $(J)$

TAIL $(J)=T A I L I+T A I-S * M E V$

SKUL O $(J)=S K U L O I+$ SKUL CS*MEV

SKUHI $(J)=S K U H I I+S<U H I S * M E V$

BETAI $(J)=P(K) * T A I L(J)$

BETA $2(J)=V S K U L$ S $(K(K) * S K U L O(J)$

BETAI $(J)=N S K U H I * P(K)$ \&KUHI $(J)$

c

$22 K=K+$

c

DETERMINE NUMBER OF FREE PARAMETERS

NFREE $=0$

DO $24 K=1$. NPRMS

IF (IHOLD(K) - EO . 1) NFREE=NFREE+1

$c$

24 CCATINUE

$c$

PFINT HEADING FOR NLLS DUTPUT

IF (IPPINT .EO. O) GO TO 26

WRITE (NPRTR, IOO) L,IMIN,IMAX, JMIN,JMAX

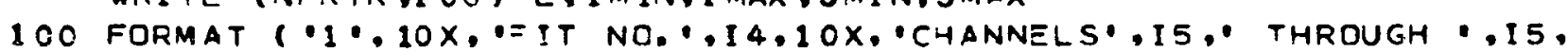

$110 \times$, FEAKS', 15, THROUGH ', I5)

WRITE (NPRTZ,1 O2) ENERGY(JMIN),P(J),P(4), TAIL(1), SKULO(1), SKUHI (1) PKFT 1420

102 FORMAT (-PARAMETERS FOR PEAK(1): ENEFGY = .F7.1. KEV =WHM DKFT1430

PKFT1090

PKFT 1100

PKF T 1110

PKFT 1120

PKFT1130

PKF T1140

PKFT 1150

PKFTI 160

PKFT 1170

PKFT 1180

PKFT1190

PKFT1 200

DKF T1 210

PKFT1220

PKFT 1230

PKF T124C

PKFT 1250

PKFT1260

PKFT 1270

PKFT1 280

DKF T 1290

PKFT 1300

PKFT1310

PKFT1 13 ?

DKFT1 330

DKF T 1340

PKFT 1350

PKF T 1360

PKFT $1 \geq 70$

DKFT1 390

PKF T 1390

PKFT 1400

PKFT1 110 


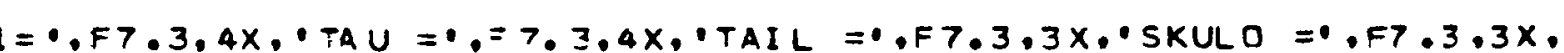
1 SKUHI $=0, F 7 \cdot 3 / 1$ HO)

PERFORM FIT

26 CALL NLLS(IDRINT)

SAVE RESULTS OF FIT

NFRSV(L) =NF REE

VARSV(L) $=$ VAR

I CNVSV (L) = I CONV

I TRNSV(L) =I TRA TN

$A S V(L)=P(N P+1)$

$B S V(L)=B P R I M E$

$k=1$

DO $30 \mathrm{~J}=J M I N, J M A X$

HEIGHT $(J)=P(K)$

PCS $(J)=P(K+1)$

FwhM $J)=P(K+2)$

TAU( J) $=P(K+3)$

$\operatorname{SCHT}(J)=S T D E(K)$

SOXO(J)=STDE $(K+1)$

$\operatorname{SCFW}(J)=\operatorname{STDE}(K+2)$

SDTAL $(J)=S T D E(K+3)$

ENEF GY(J)=EO +ECH $(\mathrm{OS}(J)$

$c$

30

$K=K+4$

c

50 CONTINUE

RETUFA

END

$c$
PKFT 1440

PKF T 1450

PKFT 1460

PKFT! 470

PKFT 1480

PKFT 1490

PKFT1500

PKFT 1510

PKF T1520

PKFT 1530

PKFT 1540

PKFT1550

DKFT1560

PKF T! 570

PKFT 1580

PKFT 1590

PKF T 1600

PKFT 1610

PKFT162.0

OKFT 1630

PKFT 1640

OKFT 1650

PKFT 1660

PKFT1670

OKFT 1680

PKFT 1690

PKF T 1700

PKFT 1710

PKFTI720

PKFT 1730

PKFT 1740

PKFT 1750

PKFT 1760

NLLSOO1O

NLLSOO20 
CCMMCN / COM3/ EO,ECH, FWHMO.FWMEV. TAUO,TAUMEV, SKULOI, SKULOS,

NLLSOO30

1 SKUHII , SKUHIS, TAILI, TAILS,NSKULC,NSKUHI, NLOI, NHI I MAX IT, ITQ.

NLLSO04C

1 EPSO,EFFS, EFMXL G,EFTERM.PKLMT, NROR, NPRTR, NPNCH

CCMMON /COME/W(200) .X(200).Y(200).NPTS.EPS(39), STDE (3Q),

1 VAR, ICONV, ITRATN, SJAREA

CCNMCA /COM7/ P(39), I HOLD(39), DERIV(38), TERM(10), A-PHA 1(9),

NLLSO050

NLLS0060

NLLSOC70

NLLS0080

1 ALPHAZ (9) . BETA1 (9), BETA2(9), BETA3(9). TAIL (9), SKULO(9), SKUHI ( 9 ).

1 NPR MS , NP, NF REE, NJ, IOPT, XFIRST, BPF IME

c

REAL $* 3$ DET, AA $(1444), A * 4(76,39)$

EQUIVALENCE (AA(1),A(1))

DIMENSION MDFNT( 8). OPRNT (8), B(38). INOI (33). IND2 (33). DELT AP (38).

1 PPRNT $(3.8,8)$

EQUI VALENCE (INDI $(1)$.DELTAP(2)

FEAL MEV

INITI AL I ZA TI DN

I CCNV $=1$

IOP $T=1$

NNF $=2$ *NFREE

$N=1$

ITRATN=C

$0=1$. E20

$M P P N T(1)=0$

$L=0$

DO $8 K=1$. NPRMS

STCE $(K)=0$.

IF (IHOLD(K) . NE. I) GCTO 8

$L=L+1$

PPFNT $(L, 1)=P(K)$

8 CCNTINUE

c

C

EVAL UATE ERROR MATRIX

NLLS 0090

NLLSO100

NLLSO110

NLLSO120

NLL $\$ 0130$

NLLSO 140

NLLSO150

NLLSO160

NLLSO170

NLL $\leqq 0180$

NLLS0190

NLLSO2:0

NLL 50210

NLLSO 220

NLLSO230

NLLS0240

NLLSO250

NLLSO?60

NLLSD 270

NLL $\$ 0280$

NLL 50200

NLLSOZOC

NLLSO 10

NLLSO $32 \mathrm{C}$

NLLSO330

NLLS0340

NLLSO350

NLL $\$ 0 \equiv 60$

NLLSO 370 
1C I TRATN=I TRATNAI

IF (ITRATN ILE. MAXIT) GO TO 12

I CCNV $=6$

GO TO 50

$120014 \mathrm{~K}=1$. NF REE

$B(K)=0$.

DO $14 L=1$, NNF

$14 A(L, K)=0$.

$O L D Q=0$

$0=0$.

DO $18 \quad I=1$. NPTS

CALL FUNCT $(X(I), Y C)$

$D I F F=Y(I)-Y C$

DO $1 \in K=1$. NFREE

$C W=W(I) * D E R I V(K)$

$B(K)=B(K)+D W * D I F F$

CC $16 L=K$. NFREE

$16 A(2 * L-1, K)=A(2 * L-1, K)+D W * D E R I V(L)$

$180=0+W(I) \neq D$ IFF $* 0$ IF

GFFNT $(M)=0$

DO $20 K=2 \cdot N=R E E$

$K 1=K-1$

DO $20 \quad L=1, K I$

C

$20 \quad A(2 * L-1, K)=A(2 * K-1, L)$

C

CHECK FOR Q CONVERGENCE. CHECK FOR FULL PRINT ARRAYS.

IF (ITRATN ILT. ITQ) GC TO 24

IF (Q LLE OLDO) GO TO 22

ICCNV $=2$

GC TC 50

22 IF ((OLDO/O-1.0) . GT. EPSO) GO to 24 I CONV $=3$

GO TO 50

24 CCNTI NUE

NLLSO380

NLLS 0390

NLLSO400

NLLSO410

NLLSO 420

NLLSO430

NLLS 0440

NLL $\$ 0450$

NLLSO 460

NLLSO470

NLLSO480

NLL $\$ 0490$

NLLSO500

NLLSO510

NLLS0520

NLLS 0530

NLLSO540

NLL $\$ 0550$

NLLSO560

NLL $\$ 0570$

NLLSO580

NLLS0590

NLLSO6OO

NLLSOE1O

NLLSOEZO

NLLSD 630

NLLSOE4O

NLLS0650

NLLS0660

NLL 50670

NLLS0680

NLLS0690

NLLS0700

NLLSO710

NLL $\$ 0720$ 
32 CALL DUMNVIAA.NFREF. 38 .OET, INDI I ND2 I

NLLSO760

IF (DET .NE. O.DO) GO TO 34

ICONV $=4$

GO TO 50

34 DO $36 \quad K=1$, NFRF.

$D E L T A P(K)=0$.

DC $36 L=1$. NFREE

36 OELTAP $(K)=0 \equiv L T A P(K) * A(2 * L-1, K) * B(L)$

ICCNV $=5$

$N=M+1$

$L=C$

OO $38 K=1$. NPRMS

IF (IHOLD $(K)$. NE. I) GC TO 38

$L=L+1$

IF ( NOO(K.4) .NE. $\equiv)$ GO TO 37

IF $\left(K \bullet G^{T} \cdot N P\right.$, GO TO 37

IF ( $A B S(D E L T A P(L)) . G T . .5)$ DELTAP(L)=SIGN(.5.JELTAD(L))

NLLSO 770

NLLSO780

NLLS0790

NLL50800

NLLSOB10

NLLS0820

NLLSO 830

NLLSOE4O

NLLSO850

NLL $\$ 0860$

NLLSO870

NLLSO8BO

NLL 50890

NLLS 0900

NLLSO910

NLLS09?0

NLLS0930 THIS STATEMENT LIMITS CENTROID CHANGE TO 3,5 CHANVELS NLLSO94O

37 CF=DELTAP $(L) / P(K)$

IF (ABS(DP) .GT. EPS (K)) I CONV=1

IF (ABS(DP).GT. 0.5) DP =SIGN(0.5.DP)

$c$ THIS STATEMENT LIMITS AL:- DAFAMETER CHANGES TO

NLLSO950

NLLS 0960

NLLS0970

NLLSO980

NLLSC990

NLLS1000

$P(K)=P(K) *(1.0+D P)$

PFFNT $(L . M)=P(K)$

38 CONT INUE

MPRNT $(M)=I T R A T N$

$K=1$

DO $42 \mathrm{~J}=1$. NJ

$M E V=(E 0+E C H * P(K+1)) / 1000.0$

ALPHA I $(J)=1 \cdot 66511 / P(K+2)$

NLLS1010

NLLS 1020

NLLS1C 30

NLLS 1 C4C

NLLS1 050

NLLS1060

NLLS 1070 
ALPHA2 $(J)=P(K+3) * A L P H A I(J)$

NLLS 1080

TAIL $(J)=$ TAILI + TAI _ S*MEV

SKULC $(J)=S K U L O I+S K U L O S * M E V$

NLLS1090

SKUHI $(J)=$ SKUHII + SKUHI S*ME V

BETAI $(J)=P(K) * T A I L(J)$

BETA $2(J)=N S K U L O * P(K) * S K U L O(J)$

BET A $3(J)=N S K U H I * P(K) * S K U H I(J)$

NLLS1100

NLLS 1110

NLLSI120

NLLS 1130

NLLS 1140

NLLS1150

NLLS 1160

BPR IME $=P(K+1)-1000$.

$c$

SAVE DIAGONAL ELEMENTS FOR ERRORS

NLLS1170

NLLS1180

NLLS1 190

$L=0$

$L L=-1$

CO $44 K=1$. NPRMS

IF (IHCLD $(K)$. NE. 1 ) GC TO 44

$L=L+1$

$L L=L L+2$

STDE $(K)=A S S(A(L L \cdot L))$

44 CCNT INUE

RETURN FOR NEXT ITERATION UNLESS ICONV $=5$

IF (ICONV. $\equiv 0.1$ ) GO TC 10

$c$

FFINT CUT CONTENTS OF FRNT ARRAYS

NLLS1200

NLLS $121 \mathrm{C}$

NLLS1220

NLLS 1230

NLLS1240

NLL $\$ 1250$

NLLS 1260

NLLS1270

NLLS 1280

NLLS 1290

NLLS1300

NLLS1310

NLLS1320

NLL $\$ 1330$

NLLS 1340

NLLS 1350

NLLS1360

NLLS1370

NLL $\$ 1380$

NLLS 1390

NLLS1400

NLLS1410

NLLS1 420 
IF (IHOL $(K)$.NE. 1) GO TO 52

NLLS 1430

$L=L+1$

WRITE (NORTR.104) K.(PFRNT $(L, M M), M M=1, M)$

NLLS 1440

NLL 51450

104 FCRMAT (I3.1PAE 14.5)

E2 CCNTINUE

IF (ICONN.LT. 5) GO TO 56

$\mathrm{Q}=0$.

$I O P T=C$

CC $54 I=1$, NOTS

CALL FUNCT(X(I), YC)

$540=0+W(I) *(Y C-Y(I)) * * 2$

OFRNT $(M)=0$

56 WRITE (NPRTR.106) (OPRNT(L).L=1.M)

106 FORMAT (') $0 . .1 P B E 14.5$ )

$58 M=0$

IF (ICONV EQ. 1) GO TO 32

IF (IFRINT . EO. O) GO TO 70

GO TO $(32,60,62.64,66,68)$. I CONV

$c$

DEINT CUT CONVERGENCE NESSAGES

c

SO WRITE (NPRTR.110)

110 FORMAT ('OI TERATION STCPPED BECAUSE Q INCREASED'I $L=0$

DC $61 K=1$. NFREE

IF (IHOLO(K) .NE. 1) GO TO 61

$L=L+1$

$P(K)=F(K)-D E L T A P(L)$

61 CCNT INUE

$G=C L D G$

GO TO 70

62 WRITE (NPRTR.112) EPSQ

12 FCRMAT ('OQ DECREASED BY LESS THAN'.1 PEB.1) GO TO 70

EA WRITE (NPRTR.114) ITRATN

NLLS1460

NLL\$1470

NLLS 1480

NLL $\$ 1490$

NLLS1500

NLLS1510

NLLS1520

NLLS1530

NLL $\$ 1540$

NLL 51550

NLLS1560

NLLS1570

NLLS1580

NLL 51590

NLLS 1600

NLLS\$ 10

NLL $\$ 1620$

NLLS 1630

NLLS1640

NLLS 1650

NLLS1660

NLL $\$ 1670$

NLLS 1680

NLLS1690

NLLS 1700

NLLS1710

NLLS1720

NLLS 1730

NLLS1740

NLLS1750

NLLS1 760

NLLS1770 
114 FCRMAT (.OMATRIX A IS SINGULAF ON ITERATION, I3)

NLL $\$ 1780$ GO TD 70

66 WRITE (NPRTR,116) ITRATN

116 FORMAT ('OCONVERGEO IN , I3.' ITERATIONS ' GO TD 70

68 WRITE (NPRTR .1 18) MAXIT c

118 FORMAT ("ODID NOT CONVERGE IN..13.' ITERATIONS')

\section{FIND VARIANCE AND ERRCFS}

70 VAR $=0 / F L O A T$ (NPTS -NFREE) SUMW $=0$.

DO $72 I=1$, NPTS

72 SUMW=SUMn+W(I) VSW=VAR/SUMW

IF (IFFINT EQ. O) SO TO 74

WRITE (NPRTZ.120) VAR.O.VSW

120 FCRMAT (.OVARIANCE $=.$, FG.2,6X. $0=1,10 E 11.4,6 \times$, VARIANEE/SUM OF IEIGHTS $=$,EI 1.4)

$740076 K=1$. NPRMS

$76 S T D E(K)=S Q R T$ (STDE $(K) * V A R)$ RETURN

ENC

c

SLBROUTINE EUNCT $(X, Y)$

CCMMCA /COM3/EO,ECH,FWHMO ,FWMEV.TAJJ.TAUMEV,SKU_OI, SCU_JS,

I SKUHII, SKUHIS.TAILI, TAILS,NSKULO.NSKUHI, NLOI, NHII, MAXIT, ITO,

1 EFSQ,EFFS, EFMXLG,EFTERM, PKLMT, NROR, NDRTR, NPNCH

CCMMON /COM7/ P(38). IHCLD(38). DERIV(38).TERM(10). ALPHAI ( 3$)$.

1 ALPHAZ (9), SET AI (9), BETA2(9), BETA 3(9). TAIL (9), SKULO(9). SKUHI (9).

1 NPRMS, NP, NFREE, NJ, IOPT, XF IPST, BPRIMF

IN TEGER REGION

FIND BACKGROUND FIRST

NLLS1790

NLLS1800

NLLS 1810

NLLS 1820

NLL $\$ 1830$

NLLS 1840

NLLS1850

NLLS 1860

NLLS 1870

NLLS1880

NLLS1890

NLLS1900

NLLS19:0

NLLS 1920

NLL $\$ 1930$

NLLS1940

WNLLS1950

NLLS1960

NLLS1970

NLLS1980

NLLS 1990

NLLS2000

FUNCOCIO

FUNCOC2O

FUNC 0030

FUNCOO4O

FUNC 0050

FUNCO060

FUNCOC7O

FUNC 0080

FUNCOO9O

FUNCO1OC

FUNCOIIO

FUNCOI20 
$x 1=x-X F I R S T$

$T E R M(N J+1)=P(N P+1)+E P R I M E * X I$

FUNCO 130

FUNCO140

$Y=T E R M(N J+1)$

FUNCO 150

FUNCO160

FUNC 0170

FUNCO 180

FUNCO190

FUNCO200

FUNCO210

FUNC 0220

$L=0$

DC $50 \mathrm{~J}=1$. NJ

$Z=A L P H A I(J) *(X-P(K+1))$

$Z 1=-Z-A L P H A Z(J)$

$22=Z * Z$

IF $(Z 1 \cdot G T \cdot 0.0) \quad Z 2=Z 2-Z 1 * Z I$

IF (Z2.GT.25.0) GO TC 8

$Z E T A=E X P(-Z 2)$

GC TO 10

8 ZETA $=0.0$

$c$

$21>$ D DEFINES REGION I

FUNCO $23 \mathrm{C}$

FUNC 0240

FUNCO250

FUNCO260

FUNC 0270

FUNCO 280

FUNC $0290^{\circ}$

FUNCO 300

FUNCO310

FUNC 0 320

FUNCO 330

FUNCO340

FUNCO350

FUNC0350

$$
Z=Z 1
$$

GAMMA $=Z * * N L O I$

DEL TA $=P(K) * Z E T A *(1 \cdot 0-T A I L(J)+\operatorname{SKULO}(J) * G A M M A * Z)$

FUNC 0370

FUNCD 380

$\operatorname{TERM}(J)=$ DELT A+BET AL (J)

$Y=Y+$ TEPM(J)

IF (IOPT .EQ. O) GO TO 50

DELTA $2=2$ - D*DELTA

ETA $=2 E T A * G A M M A * B E T A 2(\mathrm{~J})$

THETA $=A L P H A ?(J)$

c

GO TO 20

FUNC0390

FUNCO $40 \mathrm{C}$

FUNCO410

FUNC 0420

FUNCD430

FUNC $044 C$

FUNCO450

FUNC046O

FUNC 0470 
14 REGICV $=3$

GAMMA $=Z * N$ NHI

DELTA $=P(K) * Z E T A *(1.0+S K U H I(J) * G A M M A * Z)$ TERM $(J)=D \equiv L T A$

$Y=Y+T E R M(J)$

IF (IOPT EEO. O) GO TO 50

DEL TAZ $=2.0 *$ DEL TA

$E T A=Z E T A * G A M M A * B E T A 3$ (J)

THE TA $=Z$

c

\section{CALCULATE DERIVATIVES}

20 IF (IHOLC(K) .EQ. O) GO TO 24 $D R V=\operatorname{TERM}(J) / P(K)$

$L=L+1$ DERIV $(L)=D R V$

24 IF (IHOLO $(K+1)$.EO. D) 60 TO 28 CQV $=($ DELTA2 *THET A-ET A) *ALPHAI (J) IF (REGICN $E$ E. 1 ) DRV $=-D R V$ $L=L+1$

FUNCO52C

FUNC 0530

FUNC0540

FUNC 0550

FUNC 0560

FUNCDSTO

FUNC 0580

FUNCO590

FUNCOEOO

FUNC 06: 0

FUNCO620

FUNC OE 30

FUNCO64C

FUNC 0650

FUNCO650

FUNC0670

FUNC 0690

FUNCO690

FUNC 0700

FUNCC710

FUNCOT2O

FUNC 0730

FUNCOT4C

FUNC 0750

FUNC0760

FUNCO77O

FUNC 0780

FUNCOT9O

FUNC OENO

FUNCO81O

FUNC0820 
DER I V $(L)=D R V$

28 IF (IHCLC $(K+2)$.EQ. O) GO TO 32

FUNCO830 DRV $=(D E L T A 2 * 22-E T A * Z) / F(K+2)$

FUNC 0840

$L=L+1$

DERIV $(L)=D R V$

32 IF (IHOLD $(K+3)$.EO. 0$)$ GO TO 50

$D F V=C$.

IF (FEGION $\bullet E Q .11$ ORV =-ALPHAI ( $J) *(E T A+D E L T A 2 * Z)$

$L=L+I$

$D E R I V(L)=D R V$

C

$50 \quad K=K+4$

DERIV(L+1) $=1.0$

DERIV $(L+2)=\times 1$

RETUFN

END

SUBFCUT INE DUMNV $(A, N, N A, D, L, M)$

PURPOSE

INVERT A MATRIX USING DOUBLE PRECISION AFITHMETIC.

FUNCO850

FUNCOB60

FUNC 0870

FUNCOB90

FUNC 0890

FUNC0900

FUNCOSIO

FUNC 0920

FUNCO9 30

FUNC 0940

FUNC0950

FUNCO960

FUNC 0970

FUNCO980

FUNCD990

FUNC1000

FUNC1010

FUNC 1020

FUNC103C

FUNC1040

DUMVDO10

DUMVO020

DUMV0030

DESCRIDTION OF PARANETERS

A D DUSLE PRECISION I VPUT MATRIX, JESTZOYED IN COMFUTATI ON DUMVOO4O
AND REPLACED BY THE RESULTANT INVERSE.

$N$ - ORDER O= MATRIX A.

NN- FIRST DIMENSION OF THE A ARRAY.

D - RESULTANT DETERMINANT (DOUBLE PRECIS ION).

DUMV0060

DUMVDOTO

L - INTEGER WORK VECTOR OF LENGTH N.

DUMV0080

DUMVOC 90

M - INTEGER WORK VECTOR OF LENGTH N.

DUMVO100

DU MVO 1:0

METHOD

THE STANDARD GAUSS-JDROAN METHDO IS USED. THE DETERMINANT

DUMVO120

DUMVO130 
DINENSION A(1),L(1),M(1)

DCUBLE PRECISION A.D.BIGA, HOLO

DUMV0160

DUMV0170

DUMVO180

DUMVO190

DUMVO 200

SEARCH FOR LARGEST ELEMENT

$D=1.00$

$\wedge K=-N N$

DO $80 \quad K=1, N$

$N K=N K+N N$

$L(K)=K$

$M(K)=K$

$K K=N K+K$

$B I G A=A(K K)$

DO $20 J=K, N$

$I Z=N N *(J-1)$

DO $20 \quad I=K \cdot N$

$I J=I Z+I$

10 IF(DABS (BIGA)-DAES (A(IJ))) $15,20,20$

$15 B I G A=A(I J)$

$L(K)=I$

$M(K)=J$

20 CONTINUE

c

INTERCHANGE ROWS

$J=L(K)$

$I F(J-K) \quad 35.35,25$

$25 K I=K-\wedge N$

$D O 30 \quad I=1, N$

$K I=K I+N N$

$H O L D=-A(K I)$

$J I=K I-K+J$

DUMV0210

DUMV0220

DUMV02 30

DUMV0240

DUMVO 250

DUMV0260

DUMV0270

DUMV0280

D UMV0290

DUMV0 300

DUMVO310

DUMVO 320

DU MVO 330

DUMVO 340

DUMV 0350

DUMVOZ50

DUMV0 370

OU MVO 380

DUMV0390

DUMVO400

DUMVO410

DUMVO420

DU MVO 430

DUMV0440

DUMV0450

DUMV0460

DUMV0470

DUMV048C 
$A(K I)=A(J I)$

DUMV 0490

$30 A(J I)=H O L D$

DUMV 0500

JUMVOS10

INTERCHANGE COLUMNS

DUMVO520

DUMVOS 30

$35 I=M(K)$

$I F(I-K) \quad 45,45,38$

$38 J F=N N *(I-1)$

DO $40 J J=I . N$

$J K=N K+J$

$J \mathbf{I}=\mathbf{J P}+\mathbf{J}$

HOL $D=-A(J K)$

$A(J K)=A(J I)$

$40 A(J I)=H O L D$

DIVIDE COLUMN BY MINUS PIVOT (VALJE OF PIVOT E-EMEVT IS CONTAINED IN BIGAI

DUMVO540

DU MV 0550

DUMV0560

DUMVO570

DUMVOS80

DUMV 0590

DU MNO600

DUMVOE1O

DUMV0620

DUMV3630

DUMV0640

DUMV065C

DUMV0650

DUMV0670

DUMv068C

DUMVO690

DU MVO 700

DUMVO710

DUMVO 720

DUMV0730

DUMVO 740

DUMV0 750

DUMVO 760

DUMVO 770

DUMVOT80

DUMV0790

DU MVO80O

DUMV0810

DUMV O820

DC $65 J=1 \cdot N$

DU MVO830 


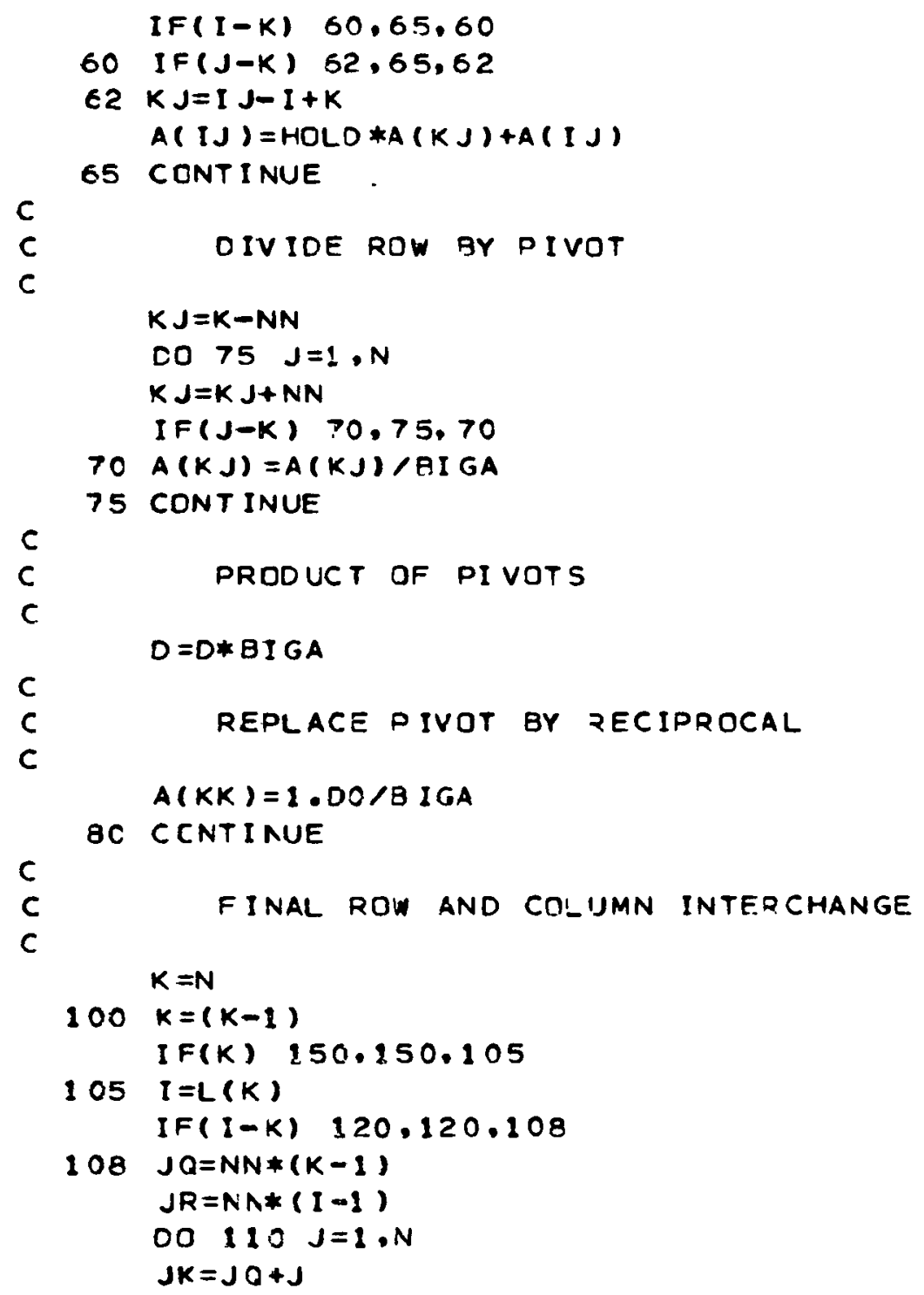

DUMV 0840 DUMVO85C

DUMV0860 DUMV0870

DUMV0880 DUMV 0890

DUMVO900

DUMV 0910

DUMVO920

DUMV0930

DUMV0940

DUMVO950

DUMVO960 DU MV 0970

DUMVO980 DUMV 0990

OUMV1000

DUMV1010

DUMV 1020

DUMV1 030

DUMV 1040

DUMVI 050

DUMV1060

OUMV $1 C>0$

DUMV1 O8O

DUMV 1090

DUMV 11 CC

DUMV 2110

OU MV $112 C$

DUNV1130

DUMV 1140

DUMV1150

DUMVII50

DUMV 1170

DUMV1180 
HOLD $=A(J K)$

$J I=J F+J$

OU MV 1190

$A(J K)=-A(J I)$

DUMV1200

DUMV 1210

$110 \mathrm{~A}(J I)=$ HOLD

DUMV1220

$120 J=M(K)$

$I F(J-K) 100.100 .125$

DUMV 1230

$125 K I=K-N A$

DO $130 \quad I=1 . N$

DUMV 1240

$K I=K I+N N$

DUMV1250

$H C L D=A(K I)$

$J I=K I-K+J$

$A(K I)=-A(J I)$

DUMV 1260

DUMV1 270

DUMV 1280

DU MV 1290

DUMV1 300

DUMV 1310

GOTO 100

DUMV1 320

RETURN

DUMV 1330

END

SUBROUT INE OUT2 (LABEL)

DU MV 1340

OUT20010

DUT 20020

COMMON /COMI/ LENGTH.NFIRST.NLAST.NWINDJ. JATA( 81.92)

CCMMON /COM2/ MAXPKS.NFEAKS.POS (250), ENERGY(250), AREA(25) ),

OUT2003A

OUT 20040

1 FWHM(250), TAU(250). NPKS(250), FI TLO(250), FITHI (250), N=ITS

OUT20050 CCNMEN / COMZ/EO .ECH,FWHMO ,FWMEV,T AJJ .TAUMEV, SKU_OI, SKU_JS.

OUT20060

OUT 20070

1 SKUHII, SKUHIS, TAILI, TAILS,NSKULO,NSKUHI, NLOI, NHI I, MAXIT, ITO,

1 EPS 2 ,EFFS, EFMXLG,EFTERM, PKLMT, NROR, NPRTR, NPNCH

COMMON /COM4/IFIT, I PRINT, IPUNCH, I GRAPH, IF IX, MLTPLT , MXFTSZ, EPSHT.

1 EPSXO,EPSFW.EPSTAU, EP SA, EPSB.DIFLIN, CONST .SEP ,FI TABV,FITBEL.

1 FITCTF,FWCTF, TAUCTF, XSF

COMMON /COMT/ P( 38). IHOLO(38), DEPIV(38). TERM(10), ALPHA1 (9),

OUT20080

OUT 20090

OUT20100

OUT20110

OUT 20120

1 ALPHA2 ( 9 ) . BET AI (9), BETA2 (9), BETA3(9), TA IL (9), SKULO(9), SKUHI (9),

1 NPR MS, NF, NF REE, NJ,I OPT, XF IRST, BPRI ME

CCMMON / COMB / NFRSV(250). ICNVSV(250). I TRNSV(250) . VARSV(250),

OUT20130

DUT20 140

OUT20150

1 HEIGHT(250), SDHT(250), SDXO(250), SDFW(250), SDTAU(250), ASV(250),

1 eSV (250), LFIT(252)

OIMENSION X(210),Y(210), YCAL(2.00),XC(201), LABEL(20)

OUT20160

OUT20170

OUT20180

DUT20190 


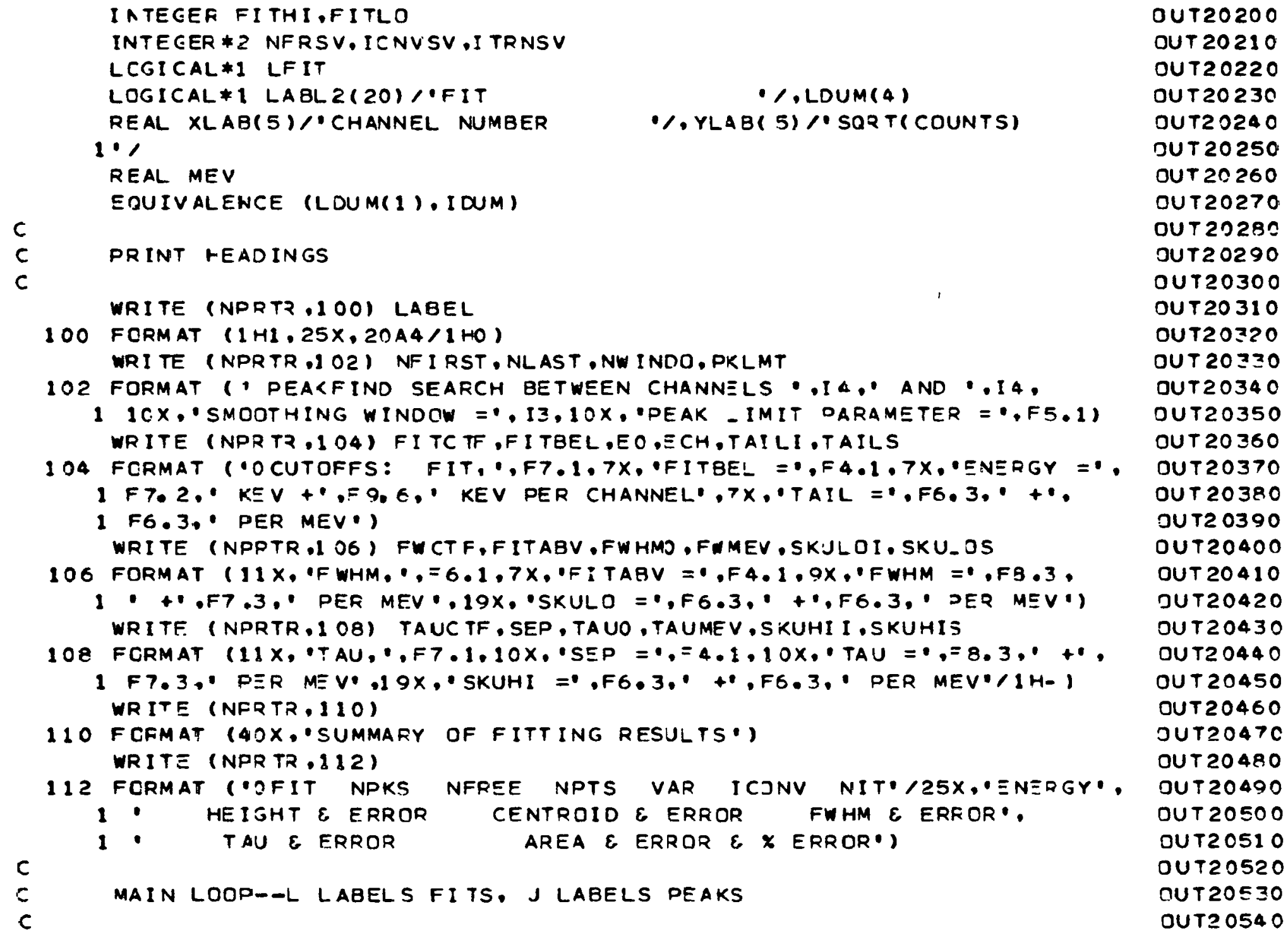




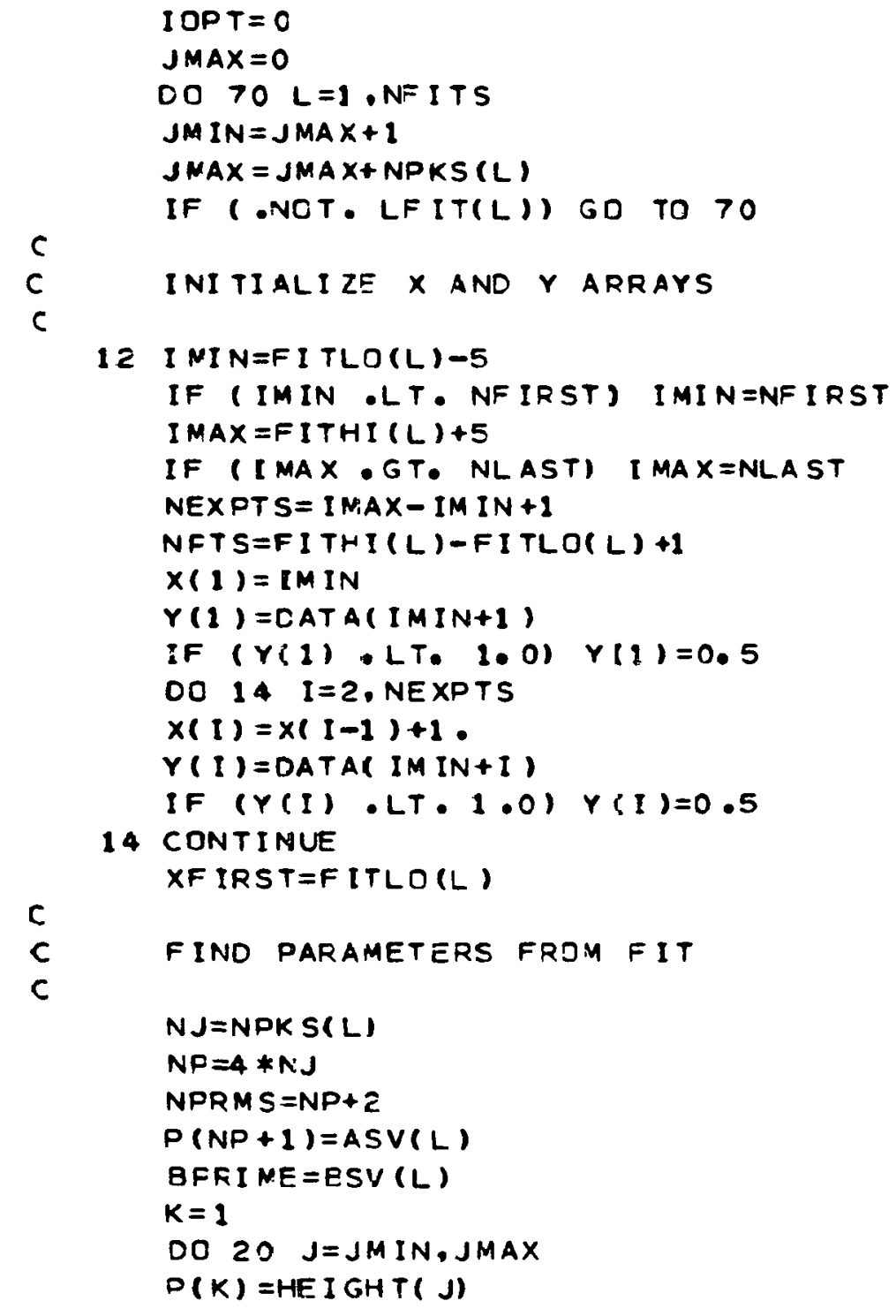

OUT 20570

OUT20580

OUT20590

OUT 20600

OUT20610

OUT20E?

OUT20630

OUT20є40

OUT 20650

OUT 20660

OUT20670

OUT20630

OUT 20685

OUT2069C

OUT2070C

OUT20710

OUT2 0720

OUT 20730

OUT 20740

OUT20750

OUT 20760

OUT2 0770

OUT 20780

OUT20790

OUT20800

OUT20810

DUT2082 O

OUT 20830

OUT20840

OUT20850

กUT20860

OUT20870

DUT 20880 


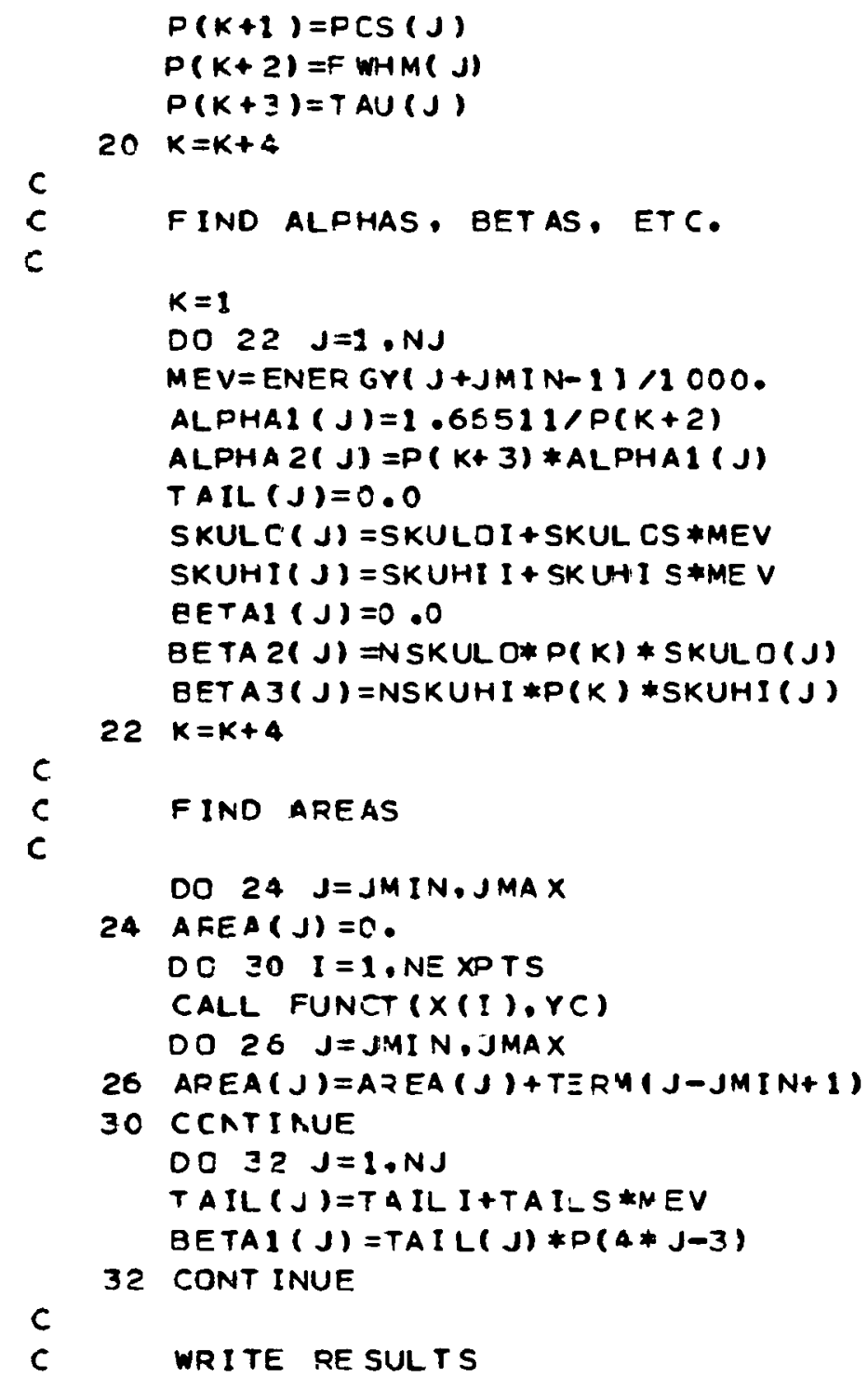

OUT20890

OUT 20900

OUT20910

OUT20920

DUT 20930

OUT20940

OUT 20950

OUT2 0960

OUT20970

DUT 20980

OUT20990

DUT 21000

OUT21010

OUTE1020

OUT 21030

OUT21040

OUT 21050

OUT21060

OUT21070

OUT 21080

OUT21090

JUT 21100

OUT21110

OUT?1120

DUT21130

OUT21140

DUT21150

OUT21160

OUT21170

OUT 21180

OUT21190

DUT21200

OUT21210

OUT21220

OUT21230 
WRITE (NPRTZ,I20) L.NPKS(L),NFRSV(L), NPTS, VARSV(L), ICNVSV(L),

1 ITRNSV(L)

120 FCPMAT (1HC.13.15.17.16.1X.F6.2.15.15)

DO $36 J=J M I N, J M A X$

ERAFEA=SORT ( (SDHT(J)/HEIGHT (J))*\#2+(SDFW $(J) / F * H M(J)) * 2)$

SEARE EA=ERAREA*AREA $(J)$

WRITE (NPRTR.122) ENER CY (J), HEIGHT(J),SDHT(J),POS(J),SOXO(J),

1 FWHN(J), SOFW(J), TAU ( J), SDTAU(J), AREA (J) , SDAREA.ERAREA

122 FORMAT (25X,F6.1.F11.1.F8.1.F12.3.F7.3.1.9.3.F7.3.F9.3.F7.3.

1 I PE 13.3,E11.3,2PFG.11

IF (IPUNCH -LT. 2) GO TO 36

WFITE (NPNCH.I24) POS (J).SOXO(J), AREA(J), HEIGHT(J), SD TT(J).

1 FWHM(J).SD=W(J), TAU(J), SOTAU(J)

124 FCRMAT (2F10.2.3F10.1.4F5.2)

C

36 CONTINUE

C DC GRAPHING

$38 X M I N=X(1)-A M O O(X(1) .10$.

IF $(X S F . L T \cdot 4.0) \times S F=4.0$

IF $(X S F, G T \cdot 20) \times S=,=20$.

$X S I Z E=(X(N E X P T S)-X M I N) / X S F$

$X S I Z E=X S I Z E+0.5-A M C O\{X S I Z E .0 .5\}$

IF $(X S I Z E \bullet L T .5 .0) \times S I Z E=5.0$

YSIZE $=8 \cdot 0$

c

PUT FIT NUMBER INTO DOSITIONS 5.6 . AND 7 OF LABL?

$c$

I $D U M=L / 200+240$

LABL $2(5)=$ LDUM( 4$)$

IDUM $=$ NOD $(-/ 10,10)+240$

LABL $2(E)=$ LDUM( 4$)$

IOUM $=$ MOC $(L .10)+240$

OUT 21250

OUT21260

OUT 21270

OUT21280

OUT21290

QUT $2130 \mathrm{C}$

OUT21310

OUT21320

OUT21330

OUT2 \&340

OUT 21350

OUT21360

OUT21370

OUT21380

JUT 21390

OUT21400

OUT21410

OUT21420

QUT21430

OUT 21440

DUT214.50

OUT21460

OUT 21470

OUT2 1480

OUT 21490

OUT21500

OUT21510

OUT21520

QUT21530

OUT21540

OUT 21550

OUT21560

OUT21570

OUT21580 


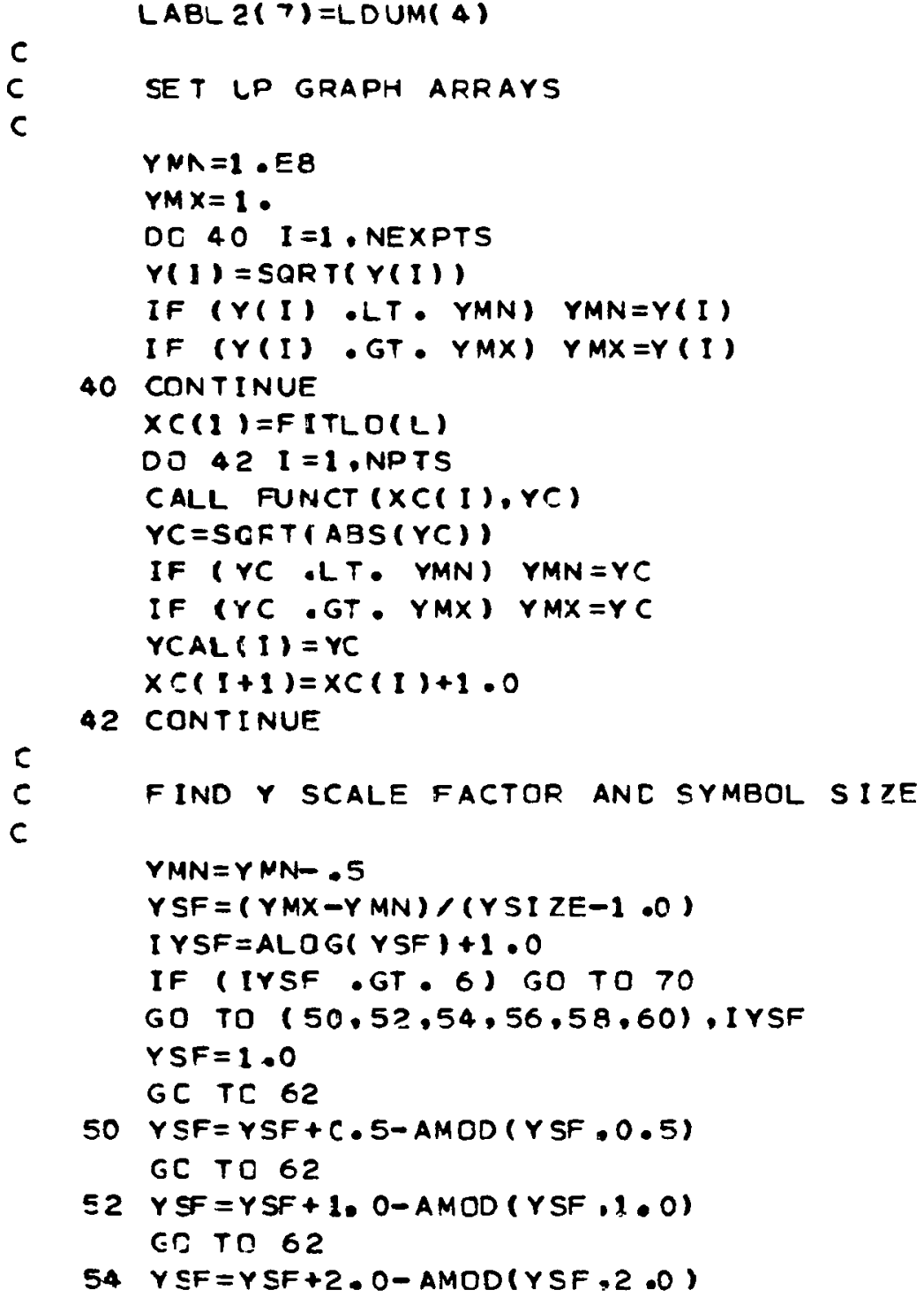

OUT 21590 OUT21600 OUT21610 OUT21620 OUT21630 DUT 21640 OUT21650 OUT $21 \in 60$ OUT21670 OUT21680 OUT 21690 OUT21710 OUT 21720 OUT21730 OUT21740 OUT 21750 OUT21760 OUT21770 OUT2178C OUT 21790 OUT 21800 OUT21810 OUT218?C OUT21830 OUT21940 OUT 21850 OUT21860 OUT 21870 OUT21880 OUT21890 OUT 21900 OUT21910 OUT 21920 DUT21930

OUT21940 
GC TC 62

$56 Y S F=Y S F+5,0-A M O D(Y S F, 5.0)$

OUT21950 GC TO 66

$58 Y S F=Y S F+20 .-A M O D(Y S F .20$.

DUT 21960

OUT21970 GO TO $E \epsilon$

60 YSF $=Y S F+50 .-A M D D(Y S F .50$.

UT21980

OUT 21990

DUT22000

GC TO $\in 6$

E2 YFIR $=Y M N-A M O D(Y M N, Y S F)$

SIZE $=1.0 / Y S F$

CALL ORIGIN(SIZE.0.5)

QUT22010

DUT22020

OUT22030

OUT 22040

OUT22050

OUT22050

CALL GRAPH (NEXPTS,X,Y.13,7,XSIZE,YSIZE,XSF,XMIN,YSF,YFIR,XLAB,

OUT22070

DUT22080

GC TC 68

66 CALL ORIGIN(0.08.0.5)

$Y F I R=Y N A-A M O D(Y M N, Y S F)$

CALL GRAPH(NEXPTS,X,Y,2,7,XSIZE,YSIZE,XSF,XMIN,YSF,YFIR,XLAB,

OUT 22090

OUT22100

OUT22110

OUT22120

1 YLAE,LABEL,LABL 2$)$

68 CALL GRAPH(NPTS,XC,YCAL.2.2.0.,YSIZE, XSF,XMIN,YSF,YFIR.0.0.0.0)

OUT 22130

c

70 CONT INUE

C

END OF MAIN LDOP

OUT22140

OUT22150

OUT22160

DUT22170

OUT2? 280

WFITE (NPRTR , 26 )

126 FORMAT (-EXPLANATION CF ICONV: 2 - O INCREASED ON LAST ITERATIONOUT22I9O $1 \cdot 124 \times, 3$ - Q DECREASED BY LESS THAN EPSO $124 \times, \cdot 4$ - ERZOP MATRIX WAOUT222OO

IS SINGULAR / $/ 24 \times, 15$ - CONVERGED NORMALLY'/24X.16 - DID NOT CONVERGEOUT2221O

1 IN MAXIT ITERAT IONS $/ 1$ IHO ) RE TURN

END

OUT22220

OUT2223C

OUT22240

I NSERT MAIN

OVERLAY ONE

INSERT INPUT

CVERLAY ONE

INSERT PKFIND 


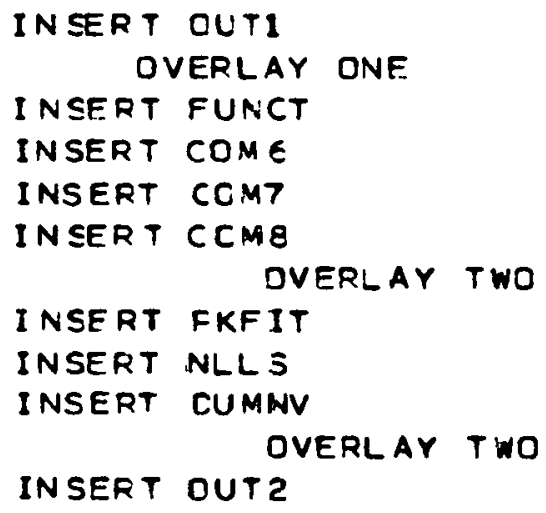

